IP Periodica Polytechnica Chemical Engineering

\author{
62(1), pp. 76-90, 2018 \\ https://doi.org/10.3311/PPch.10543 \\ Creative Commons Attribution (i)
}

RESEARCH ARTICLE

\section{Complex Treatment for the Disposal and Utilization of Process Wastewaters of the Pharmaceutical Industry}

Erika Szabados ${ }^{1}$, Andrea Jobbágy ${ }^{2}$, András József Tóth ${ }^{3}$, Péter Mizsey ${ }^{3,4}$, Gábor Tardy², Cesar Pulgarin ${ }^{5}$, Stefanos Giannakis ${ }^{5}$, Erzsébet Takács ${ }^{6}$, László Wojnárovits ${ }^{6}$, Magdolna Makó ${ }^{7}$, Zénó Trócsányi ${ }^{8}$, Antal Tungler ${ }^{1 *}$

Received 26 January 2017; accepted after revision 27 April 2017

\begin{abstract}
A complex treatment of process wastewaters (PWW) of the pharmaceutical industry has been elaborated, the objective was their common disposal and utilization. The biodegradability of polluting components is concentration dependent, the mixing of PWWs with domestic wastewater at WWTP is possible, if no toxic and/or non-biodegradable components are present. So the organic content can serve as carbon source in the denitrification step. The characterization and the proper treatment methods of PWWs have been developed. Only 20-30\% of $P W W$ s required pretreatment. The majority can be mixed directly with the domestic wastewater and send to the WWTP. The characterization includes COD, TOC, BOD, AOX, volatile content, toxicity, metal ion content measurements. The pretreatment methods could be: distillation, WO or catalytic WO. After the activated sludge treatment the degradation of emergent pollutants and the disinfection can be performed by UV-Fenton or high energy irradiation. The design of a complex treatment plant attached to a WWTP of $100000 \mathrm{~m}^{3} /$ day capacity and its life-cycle analysis to determine the environmental benefits were carried out also.
\end{abstract}

\section{Keywords}

pharmaceutical process wastewater, disposal, utilization, distillation, WAO, activated sludge treatment

\footnotetext{
${ }^{1}$ Department of Surface Chemistry and Catalysis, Centre for Energy Research, Hungarian Academy of Sciences, 1525 Budapest, 114 P.O.B. 49, Hungary ${ }^{2}$ Department of Biotechnology and Food Science, Budapest University of Technology and Economics, H-1521 Budapest, P.O.B. 91, Hungary

${ }^{3}$ Department of Chemical and Environmental Process Engineering, Budapest University of Technology and Economics,

H-1521 Budapest, P.O.B. 91, Hungary

${ }^{4}$ University of Miskolc, Hungary

${ }^{5}$ Institut des Sciences et Ingénierie Chimiques, GGEC, EPFL, Bât. CH, 1015 Lausanne, Switzerland

${ }^{6}$ Department of Radiation Chemistry, Centre for Energy Research, Hungarian Academy of Sciences, 1525 Budapest, 114 P.O.B. 49, Hungary

${ }^{7}$ Budapest Sewage Works, 1087 Budapest, Asztalos Sándor út 4., Hungary

${ }^{8}$ Geosan Ltd., 1118 Budapest, Brassó út 169-179., Hungary

*Corresponding author, e-mail: tungler.antal@energia.mta.hu
}

\section{Introduction}

The demand of a sustainable and feasible disposal of water containing liquid wastes of high organic content was the driving force of recent research carried out by a consortium which consisted of academic (MTA EK, Centre for Energy Research, Hungarian Academy of Sciences, BME, Budapest University of Technology and Economics, Department of Applied Biotechnology and Food Science, Department of Chemical and Environmental Process Engineering, EPFL, École Politechnique Fédérale de Lausanne, Advanced Oxidation Processes Group) and industrial partners (FCSM, Budapest Sewage Works, Geosan Ltd.). This work was financed by a Jedlik (NKTH) and a Swiss-Hungarian Cooperation (SH) project.

The antecedents of the two projects were researches carried out at BME [1-3] and MTA EK [4, 5], and in the case of the SH project at EPFL [6-8]. These covered the biological, chemical, distillation, high energy irradiation and AOP treatment methods.

The PWWs originating from the fine chemical industry cannot be fed directly into municipal sewer systems due to their high, often toxic and/or non-biodegradable organic content. Simple dilution of these wastes with tap-water or industrial water is prohibited. What are the possible solutions of treatment? Ranking according to their environmental effect they are: incineration, wet oxidation (WO), distillation, membrane separation, activated sludge treatment [4]. The last option is the most environmentally benign and has the highest capacity. Moreover in activated sludge treatment of wastewaters with limited carbon availability (which occurs frequently in Hungary and Eastern Europe [9, 10]), possible utilization of the PWWs as excess carbon source for denitrification is also economically advantageous. Treatment and utilization in biological wastewater technologies, however, is only available for biodegradable wastes. Therefore the idea presented itself that mixing of the PWWs with large amount of municipal wastewater, because of the changing biodegradability with concentration (see Monod [10] and Andrews kinetics [11]), the combined activated sludge treatment becomes possible. In order to verify this assumption it was necessary to determine the appropriate characterization methods of the PWWs and to test the proportion of the PWWs 
requiring pretreatment because of their toxicity and/or non-biodegradability $[12,13]$.

The available characterization methods (COD, TOC, BOD, AOX, volatile content, toxicity, metal ion content) and the possible pretreatment processes (WO, distillation, membrane separation) were investigated in detail in our laboratories. The actual tasks were the selection of the most useful characterization and pretreatment methods. The difficulties reside in addition in the constantly changing composition of the PWWs of the pharmaceutical industry and in the prerequisite of scale-up possibility of the methods to be applied. In the two projects the pilot-scale experiments of the treatments methods were pledge and commitment as well.

\section{Experimental}

\subsection{Wastewaters and their characterization}

The tested samples were two kinds: model wastewaters made of single pollutants and process wastewaters collected from the pharmaceutical companies. The latter were treated as "black boxes", their volatile organic content, metal ion content, COD, TOC and BOD values were measured, and their anaerobic digestion and oxidation properties determined.

\section{Chemical characterization, COD and TOC measurements}

COD was determined by the standard dichromate method. The TOC was determined by a Shimadzu TOC analyzer whose operation was based on catalytic combustion and non-dispersive infrared (NDIR) gas analysis.

\section{Biodegradation characterization}

The behavior of the PWWs was investigated by aerobic respirometric tests and anaerobic digestion tests. The toxicity and/or biodegradability was estimated on the basis of oxygen consumption in aerobic activated sludge respirometry, the formation of biogas in batch digestion experiments as well as on the measured residual COD at the end of the biodegradation processes. The aerobic respirometric tests were carried out in a WTW OxiTop device, measuring the oxygen consumption over 5 or 10 days $\left(\mathrm{BOD}_{5}, \mathrm{BOD}_{10}\right)$. In order to investigate the concentration dependence of the biodegradation, respirometric measurement of the PWWs was conducted in different dilutions. Aimed initial concentration range of the investigated PWWs was generally between 25 and $800 \mathrm{mg} \mathrm{COD} / \mathrm{L}$ in this measurement. For dilution peptone solutions were used providing biodegradable carbon source for possible co-metabolic processes, complemented with inorganic salt components of $\mathrm{NH}_{4} \mathrm{Cl}, \mathrm{K}_{2} \mathrm{HPO}_{4}, \mathrm{KH}_{2} \mathrm{PO}_{4}, \mathrm{MgCl}_{2}, \mathrm{CaCl}_{2}$. Effluent water from the secondary clarifier of the South-Pest Wastewater Treatment Plant (WWTP) was used for seeding (seeding was provided by the residual suspended biomass). Oxygen consumption coupled with nitrification was eliminated by adding allyl thiourea. On respirometric curves the oxygen consumption is given in $\mathrm{mg} / \mathrm{L}$ units calculated for the non-diluted PWW. BOD $_{5}$ was measured according to DIN EN 1899-1, also with an OxiTop device.

Denitrification measurements have been carried out in 2.51 zero head-space reactors [15]. Activated sludge was used as the seeding biomass, while the water of the final aerobic basin of the South-Pest WWTP was used as the diluting medium. Three different initial concentrations of the investigated PWW have been applied: 100, 200 and $300 \mathrm{mg} C O D / 1$. The initial nitrate concentration was $400 \mathrm{mg} / \mathrm{l}$. Samples were withdrawn every 30 minutes over 9 hours and their nitrate, nitrite and COD values were measured.

\section{Determination of the volatile organic content}

The volatile organic content of the process wastewaters was measured with a distillation probe and subsequent GC analysis, where the most common components (methanol, ethanol, ethyl acetate, acetone, etc.) could be identified and their concentration determined. In addition, initial batch rectification experiments were carried out for every PWW. The experiments were evaluated and the PWWs where the batch rectification resulted in significant COD reduction were further investigated. The PWWs of high VOC were also rectified in continuous mode in a pilot plant laboratory column with 14 theoretical plates.

\section{XRF determination of metal content of wastewaters}

The metal content of PWW's can be detected preferably by $\mathrm{X}$-Ray fluorescence spectroscopy using one-point calibration [13].

\section{Oxidation procedures}

The samples were oxidized in 30,250 and $850 \mathrm{ml}$ stainless steel high pressure autoclaves equipped with magnetic stirrer (rpm 700), in a temperature range of $100^{\circ} \mathrm{C}$ to $250^{\circ} \mathrm{C}$, at total pressures from 15 to 50 bar, for 1 to 5 hours. Some samples were mixed with $\mathrm{NaOH}$ solution until $\mathrm{pH}=14$ and then were diluted, if it was necessary, to $\sim 50000 \mathrm{mg} / \mathrm{l}$ COD value and subsequently oxidized.

Because of the organic acid and $\mathrm{CO}_{2}$ formation the basic $\mathrm{pH}$ was advantageous from the point of view of corrosion and catalyst leaching also.

The Na-phenolate solution was prepared by dissolving 18.8 $\mathrm{g}$ phenol and $8 \mathrm{~g} \mathrm{NaOH}$ in 21 distilled water (COD $21194 \mathrm{mg} / 1$, TOC $7453 \mathrm{mg} / \mathrm{l}$ ).

The DMF was dissolved in distilled water $(11.5 \mathrm{~g} / 1,157$ $\mathrm{mmol} / \mathrm{l})$. The parameter ranges of WO were $\mathrm{T}=180-220{ }^{\circ} \mathrm{C}$, $\mathrm{p}_{\mathrm{O} 2}=8-24$ bar, $\mathrm{t}=1-5 \mathrm{~h}$, the stirrer speed was fixed at $750 \mathrm{rpm}$, as in preliminary experiments it has been proved to be in the kinetic regime.

The autoclaves were pressurized with oxygen to 5 bar, and heated up to the desired temperature with continuous stirring until the given reaction time. The pressure was maintained at the desired value by dosing oxygen during the experiments. 
Samples were taken periodically and/or at the completion and then were analyzed.

In the case of CWO (catalytic WO) experiments, the monolith catalysts ( $\mathrm{Ti}$ meshes covered with $\mathrm{Ru}, \mathrm{Ir}$, Pt containing layer) was rolled and placed into the autoclaves (standing against the inner wall) before filling the reactor with wastewater. In some experiments for determining the conversion-time relationship, liquid samples of approximately $3 \mathrm{ml}$ were periodically withdrawn from the reactor through a tube located at its bottom. The outer section of the tube was water-cooled in a jacket for decreasing the sample temperature. Before taking each sample, the dead volume of the tube (about $7 \mathrm{ml}$ ) was disposed of, that is why it was necessary to work at least with $200 \mathrm{ml}$ reaction mixture. Since the applied oxidation procedure is a batch-wise reaction in an autoclave under high pressure, the majority of volatile compounds and the formed $\mathrm{CO}_{2}$ are dissolved in the aqueous phase, the latter as carbonate at the basic $\mathrm{pH}$.

Prior to oxidation experiments the COD, TOC, $\mathrm{pH}$ values of the model and real wastewater samples were measured.

The catalysts were characterized beside oxidation measurements with PGAA (prompt gamma activation analysis), TPR (temperature programmed reduction), SEM-EDX (scanning electron microscopy, with energy dispersive X-ray spectroscopy), ICP-MS (inductively coupled plasma mass spectrometry) and XPS (X-ray induced photoelectron spectroscopy) [14].

\section{Results and discussion}

In the course of the two projects more than 30 different real PWWs, received from 3 pharmaceutical companies in Budapest, were investigated in detail. Their characteristic properties were determined, distillation probes, WO experiments, and aerobic, anaerobic biodegradation tests were carried out [4, $13,15]$. Their results served for the basis of the assignment and the determination of the required treatment procedures.

\section{Classification of $P W W S$}

Based on the COD, TOC and BOD values PWWs can be divided up to (i) biodegradable mixed with municipal wastewater in 500-1000x ratio $\left(\mathrm{BOD}_{5} / \mathrm{COD}\right.$ ratio $\left.>0.7-0.8\right)$, (ii) non-biodegradable and/or toxic. According to the data of real PWWs the first group covers approximately 2/3-4/5 part of them [13]. The remaining part consist of three groups distinguished by the required treatment: (i) requiring distillation because they have volatile content of several percentage that encumbers biodegradation, (ii) needed WO because of recalcitrant components, (iii) a few of the total amount require both distillation and WO, in this order.

The testing of model wastewaters (in distillation: aqueous solution of dichloromethane, in WO: that of phenol, acetic acid, diclofenac, dimethylformamide, paracetamol, in activated sludge treatment (BOD measurements): reaction mixtures of the WO experiments served information primarily about the capabilities and limitations of the aforementioned methods in laboratory scale.

Besides the experiments with real wastewaters the testing of model aqueous solutions of possible pollutants served also with valuable data especially for the scaling up procedure. In series of designed experiments (DOE) the parameter dependence of the reactions, first of all that of the WO and $\mathrm{CWO}$ could be determined and compared.

The main conclusions of the laboratory experiments were:

1. The mixing of the PWWs with municipal wastewater may increase biodegradability. In appropriate dilution (typically in lower than $300 \mathrm{mg} \mathrm{COD} / 1$ concentration), majority of the investigated PWWs proved to be easily biodegradable. Dilution may also decrease possible toxicity. Case study of PWW no. 4982 depicted in Fig. 1., shows that original PWW diluted in different extent caused oxygen consumption decrease compared to the oxygen consumption of a reference: the diluting water containing readily biodegradable organics. This result indicates toxic effect. The toxic effect, however, is decreased by increasing the dilution above 500x. Respirometric results of the pre-treated oxidized samples show that the toxic effect of the PWW was eliminated, and part of the previously non-biodegradable pollutants were converted to biodegradable organics by wet air oxidation pre-treatment.

2. The distillation is more beneficial in comparison with stripping due to its lower energy consumption (Fig. 2), the effectiveness of removal for AOX, dichloromethane is 8 ppm in the bottom product [(17)]. The resulting distillates can be used for less demanding purposes than pharmaceutical production, for instance as solvents for paints.

3. The necessary temperature $\left(180-250^{\circ} \mathrm{C}\right)$ and pressure (15-60 bar) of WO, in order to reach the desired COD conversion, depend significantly on the chemical nature of the pollutants in the PWW, the catalytic reaction can be carried out in several cases on lower temperature with acceptable reaction rate until sufficient conversion and biodegradability. Designed Experiments increased the liability of the WO results (Fig. 3/a-d). According to the reaction rates the oxidations (both catalytic and non-catalytic ones) have two periods (I, II). In the first period up to $\sim 2$ hours the rate is much higher than in the second one. In the I the larger molecular weight components, in the II the intermediate products (largely small molecular weight carboxylic acids) are oxidized $[13,16,18]$.

4. The accessing of biodegradability requires only partial COD conversion (usually $<40 \%$, achievable in the aforementioned period I) in $\mathrm{WO}$, moreover the remaining biodegradable organic compounds serve as carbon source in denitrification in the following activated sludge treatment [17]. 
5. Both the UV-Photo Fenton process and the high energy electron beam irradiation (Fig. 5) can eliminate the major proportion of the emergent pollutants and the microorganisms in the effluents of the WWTPs [8, 18-21].

Average percentage of micro-pollutants removal is around $80 \%$ within 40 minutes by Photo-Fenton UV (UV254 + 10 $\mathrm{mg} / 1 \mathrm{H}_{2} \mathrm{O}_{2}+5 \mathrm{mg} / \mathrm{Fe}^{3+}$ ).

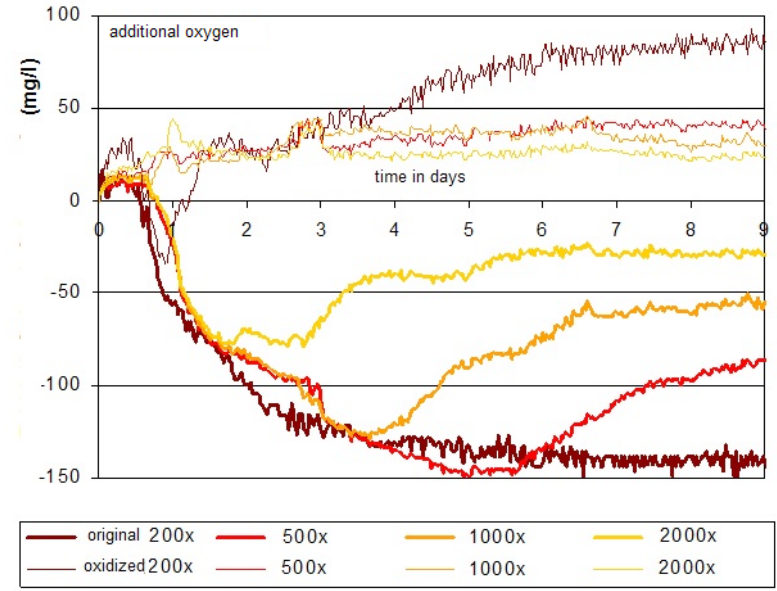

Fig. 1 Comparative respirometry measurement results for a real wastewater (4982) originated from pharmaceutical industry. Oxygen consumption difference has been calculated by subtracting the oxygen consumption measured in the diluted PWW from the oxygen consumption measured in the diluting basic solution containing readily biodegradable organics.

\section{COD values in Feed (F) and Bottom (W)}

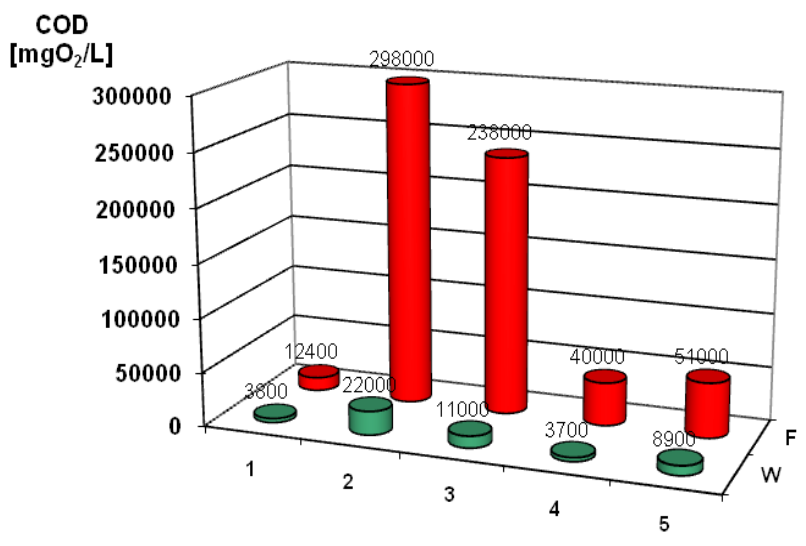

Fig. 2 Effectiveness of COD removal in the distillation of 5 different PWWs

\section{Pilot scale experiments}

\section{Pretreatment processes}

\section{Distillation}

The starting organic solvent content of the tested wastewaters were in rather wide range, see Fig. 2, but in every case nearly solvent free water and high organic content solvents could be produced with rectification in the pilot scale column
(Fig. 6) with acceptable reflux ratio and distillate removal rate. Depending on the solvent type, on the possible direct usage of the PWW in denitrification as carbon source (non-toxic) one has to decide between distillation and activated sludge treatment. An important consideration is also, whether the distillate solvent can be utilized [17].

Table 1 Removal efficiency of distillation of PWWs

\begin{tabular}{|c|c|c|c|c|c|c|}
\hline & \multirow{2}{*}{$\begin{array}{l}\mathrm{R}= \\
\mathrm{L} / \mathrm{D}\end{array}$} & \multicolumn{2}{|l|}{$\mathrm{D}$} & \multirow{2}{*}{$\begin{array}{l}\mathrm{D} / \mathrm{F} \\
\text { ratio }\end{array}$} & \multicolumn{2}{|c|}{$\mathrm{W}$} \\
\hline & & $\begin{array}{l}\text { Org. solvents } \\
{[\mathrm{m} / \mathrm{m} \%]}\end{array}$ & $\begin{array}{l}\mathrm{T} \\
{\left[{ }^{0} \mathrm{C}\right]}\end{array}$ & & $\begin{array}{l}\text { Org. solvents } \\
{[\mathrm{m} / \mathrm{m} \%]}\end{array}$ & $\begin{array}{l}\text { AOX } \\
{[\mathrm{ppm}]}\end{array}$ \\
\hline 1 & 10 & 65.3 & 87.3 & 0.01 & 0.14 & 2 \\
\hline 2 & 4 & 75.6 & 83.2 & 0.19 & traces. & - \\
\hline 3 & 4 & 99.8 & 64.8 & 0.26 & traces & - \\
\hline 4 & 10 & 11.9 & 93.5 & 0.26 & 0.06 & - \\
\hline 5 & 10 & 94.1 & 76.5 & 0.07 & 0.32 & $8.5 \mathrm{E}-03$ \\
\hline
\end{tabular}

\section{Wet oxidation}

A laboratory circulation wet oxidation device (net volume $440 \mathrm{~cm}^{3}$ ) (Fig. 7) has been built and experiments were carried out therein in batch mode. The results verified that the reaction rate in the loop reactor mixed by the mammoth-pump effect of the oxygen feed were similar to the rates in the magnetically stirred autoclaves (Table 2). From these data reaction rate values and residence times were calculated which served for the design of a pilot-scale device. Fortunately there were available two tubular, high pressure reactors made of stainless steel with 101 net volume apiece, which could be used as the upstream and downstream side of the loop reactor. The circulation was maintained beside the oxygen inlet and bubbling with a high pressure Magnepump device. The reactors had mantles for the heating, the agent was a refractory oil that was heated in an insulated tank by electric heating and circulated by a centrifugal pump through the mantles of the reactor tubes.

The scheme of the pilot scale oxidation device is on Fig. 8, the photo of the plant at Geosan in Pétfürdő is on Fig. 9. The pilot scale experiments were carried out with PWWs of pharmaceutical origin. The experimental parameter ranges were: reactor temperature $220-250^{\circ} \mathrm{C}$, oxygen partial pressure $10-30 \mathrm{bar}$, oxygen mass flow 200-1200 N1/hour, residence time 2-8 hours.

Table 2 Reaction rate ranges for analyzing data of 20 PWWs of different origin

\begin{tabular}{lllll}
\hline $\begin{array}{l}\text { Rates and outputsin } \\
\text { mg/liter x minute }\end{array}$ & $\begin{array}{l}\Delta \text { COD in } \\
\text { period I }\end{array}$ & $\begin{array}{l}\Delta \text { COD in } \\
\text { period II }\end{array}$ & $\begin{array}{l}\Delta \text { TOC in } \\
\text { period I }\end{array}$ & $\begin{array}{l}\Delta \text { TOC in } \\
\text { period II }\end{array}$ \\
\hline Rate ranges & $36-380$ & $11-55$ & $25-140$ & $3-8$ \\
$\begin{array}{l}\text { Output during 30 } \\
\text { minutes in mg/l }\end{array}$ & $1080-11400$ & $330-1650$ & $750-4200$ & $90-240$ \\
\hline
\end{tabular}




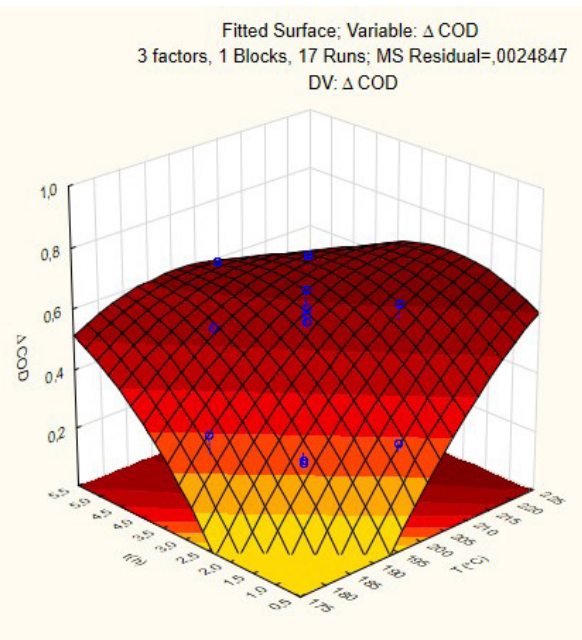

a)

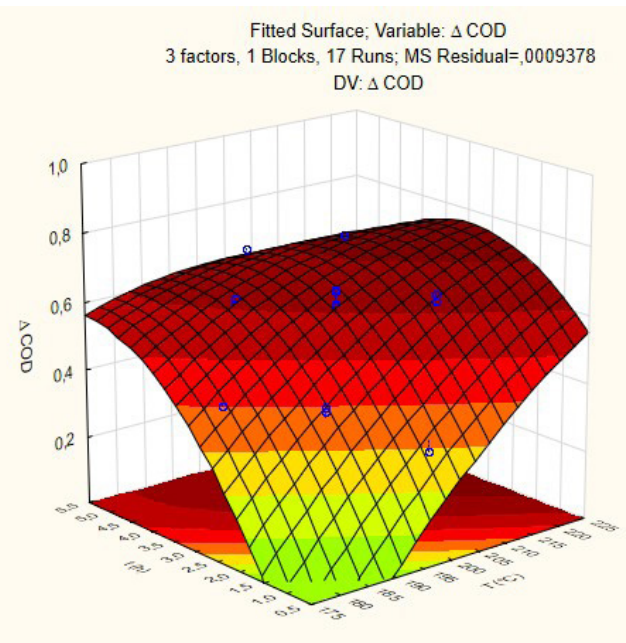

c)

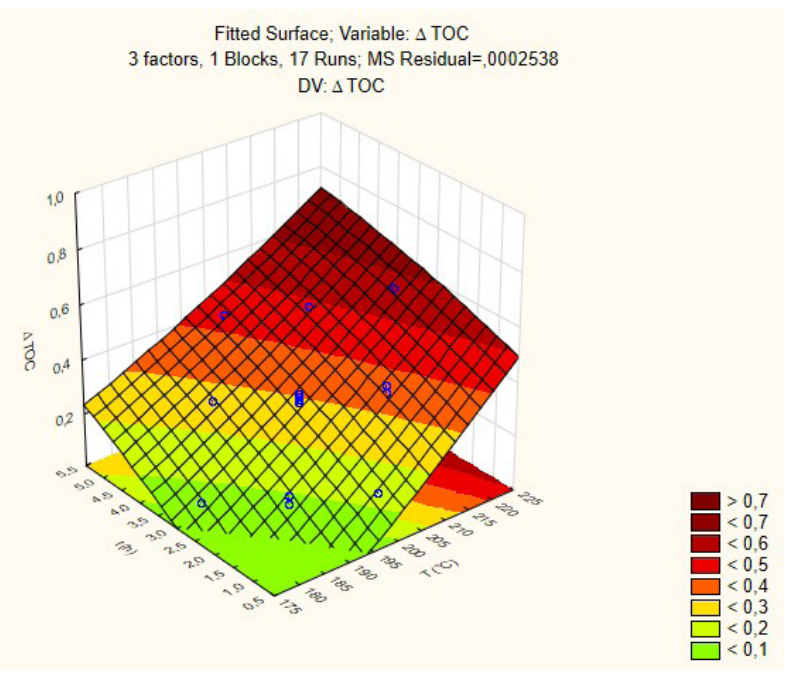

b)

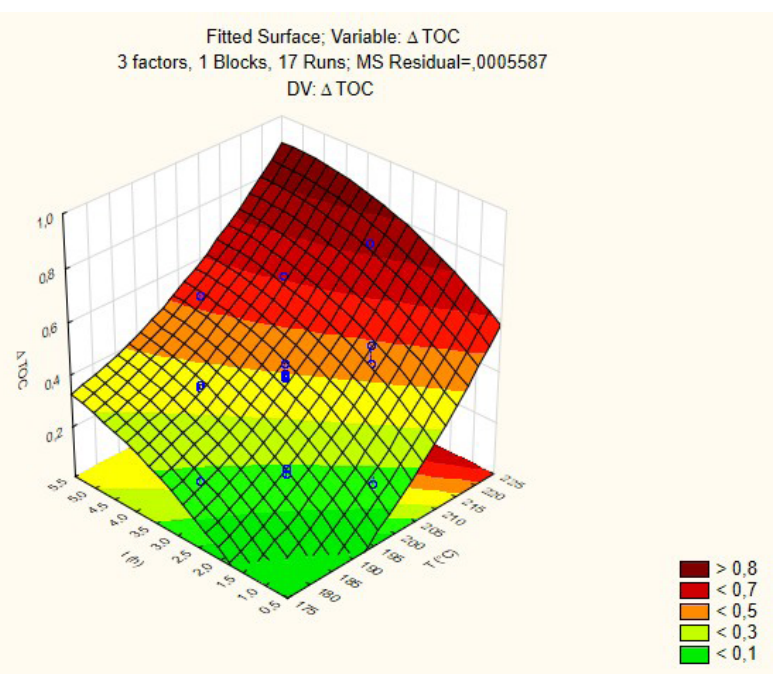

d)

Fig. 3 Response surfaces of the fitted models for (a) $\triangle$ COD conversion in thermal oxidation reaction, (b) $\Delta T O C$ conversion in thermal oxidation, (c) $\Delta C O D$ conversion in catalytic wet oxidation (d) $\triangle \mathrm{TOC}$ conversion in catalytic wet oxidation

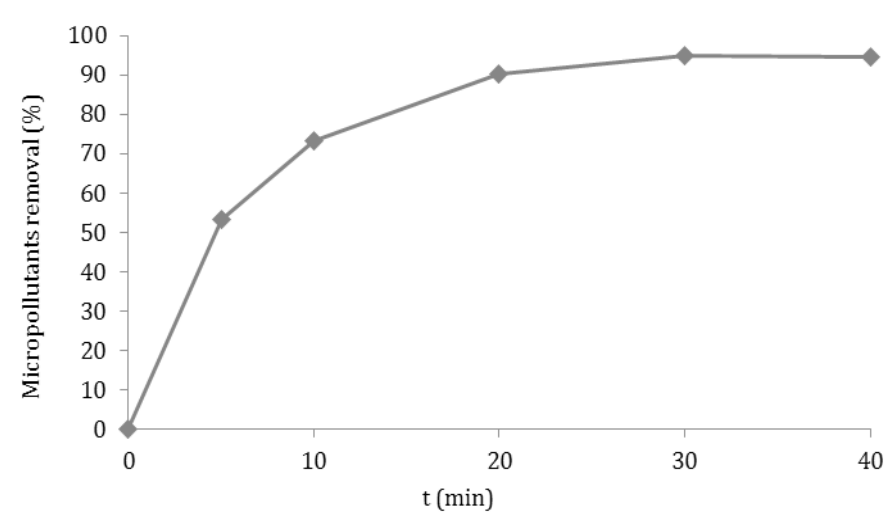

Fig. 4 The effectiveness of Photo-Fenton treatment

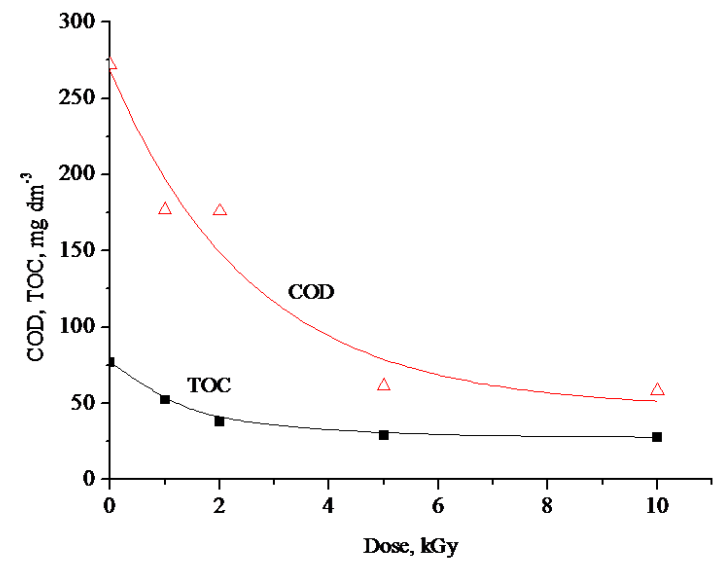

Fig. 5 Degradation of ketoprofen by high energy electron irradiation 

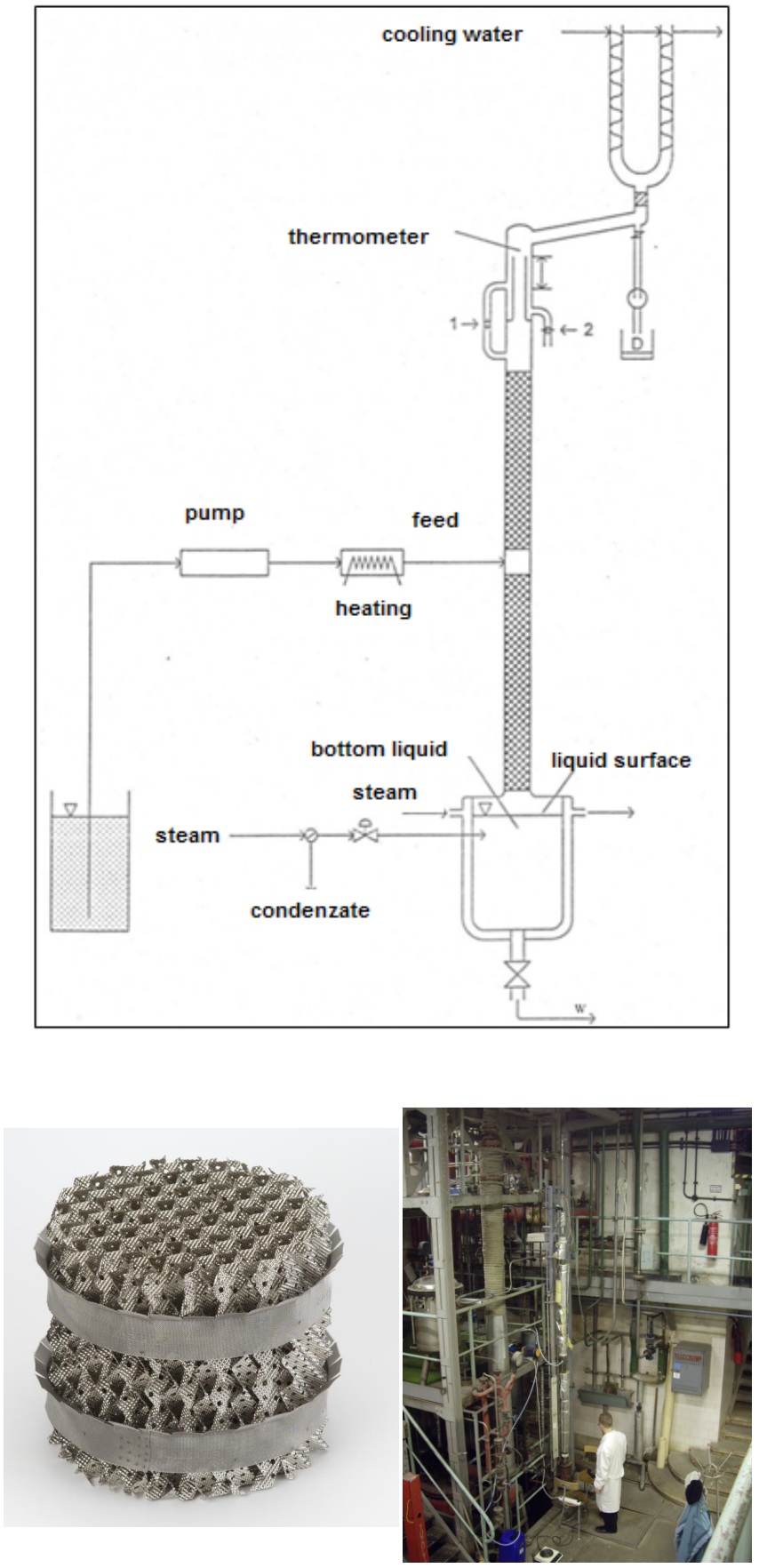

Fig. 6 Pilot plant continuous rectification column with packing

The conclusions were:

- wet oxidation decreased COD values of PWWs with $10-60 \%$,

- effect of temperature was not significant in this range,

- increase of residence time from 2 to 8 hour increased COD reduction only with $30 \%$

- increase of the partial pressure and mass flow of oxygen increased COD reduction nearly proportionally.

Summarizing the conclusions, the optimal parameters could be for the pilot scale device: temperature $230^{\circ} \mathrm{C}$, total pressure 50 bar, average residence time 3 hour, oxygen mass flow 500 Nl/hour. A warning sign was a sudden strong corrosion of the

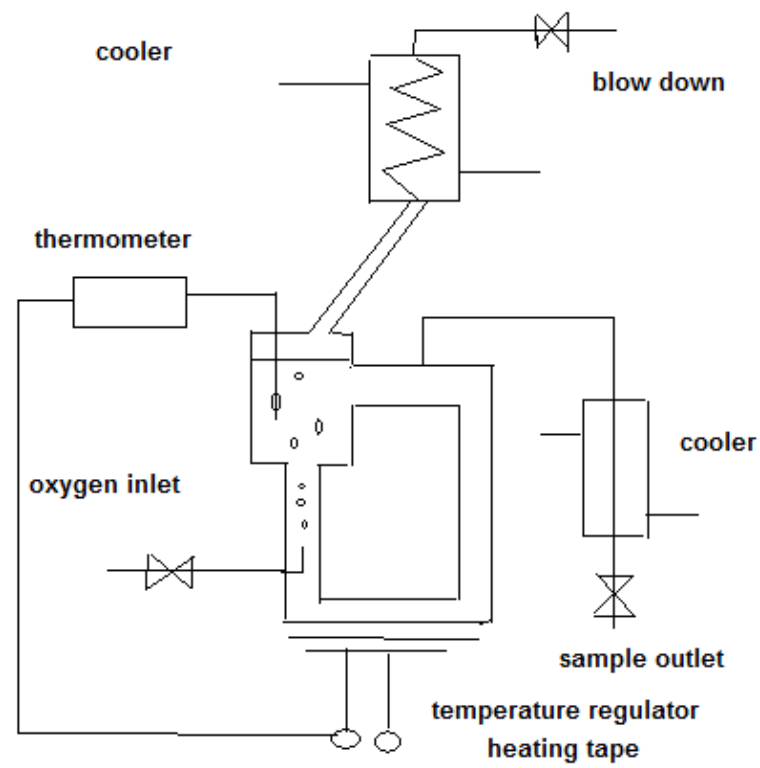

Fig. 7 Scheme of the laboratory loop reactor

stainless steel tubing and equipments during the oxidation of a PWW containing $\mathrm{NH}_{4} \mathrm{Cl}$, such toxic wastewaters have to be incinerated.

\section{Activated sludge treatment}

The activated sludge co-treatment of PWWs received from a pharmaceutical company and proved to be non-toxic and biodegradable (with $410000 \mathrm{mg} / \mathrm{l}$ COD concentration) was investigated in a pilot scale device equipped with the same functional units as a real WWTP. The PWW applied in this investigation had been previously tested in batch denitrification experiments carried out in „No-head space” reactors. These preliminary experiments suggested that organic content of this PWW is appropriate for denitrification, in the investigated $100-300 \mathrm{mg}$ COD/1 concentration range.

Main aim of the experiment was to verify the applicability of the PWW as carbon source for denitrification in continuous-flow wastewater treatment biotechnologies. Pilot-scale pre-denitrification activated sludge systems have been applied in this investigation with a total volume of 12.51 (see Fig. 10).

In the experiment domestic wastewater mimicking artificial wastewater has been applied as basic influent. In the continuous 30 days long study comparative investigation of denitrification efficiency of a test system receiving the basic influent and a reference system receiving the basic influent complemented with the above mentioned PWW has been carried out. This PWW has been dosed to the influent of the test system in the concentration range of $\sim 40-185 \mathrm{mg} \mathrm{COD} / \mathrm{l}$. Despite the increasing dosage to the test system, no toxic effect has been observed on nitrification, which is one of the most susceptible biological process to toxicity. As a result effluent $\mathrm{NH}_{4}-\mathrm{N}$ concentration values were below $2 \mathrm{mg} / \mathrm{l}$ during the whole experiment (see Fig. 11A). On the other hand, by the dosing of PWW to the test system, the 


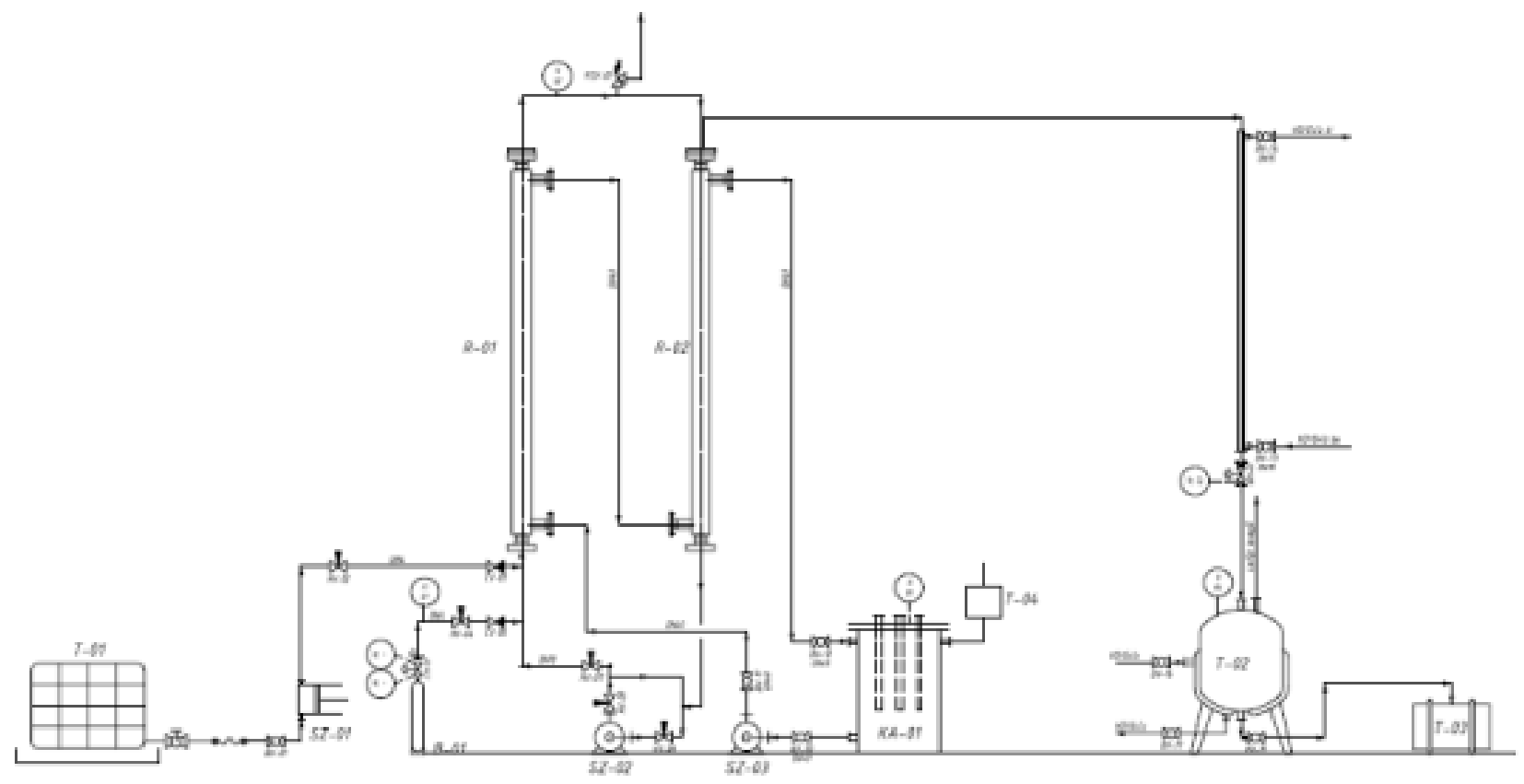

Fig. 8 Scheme of the pilot-scale loop reactor for wet oxidation

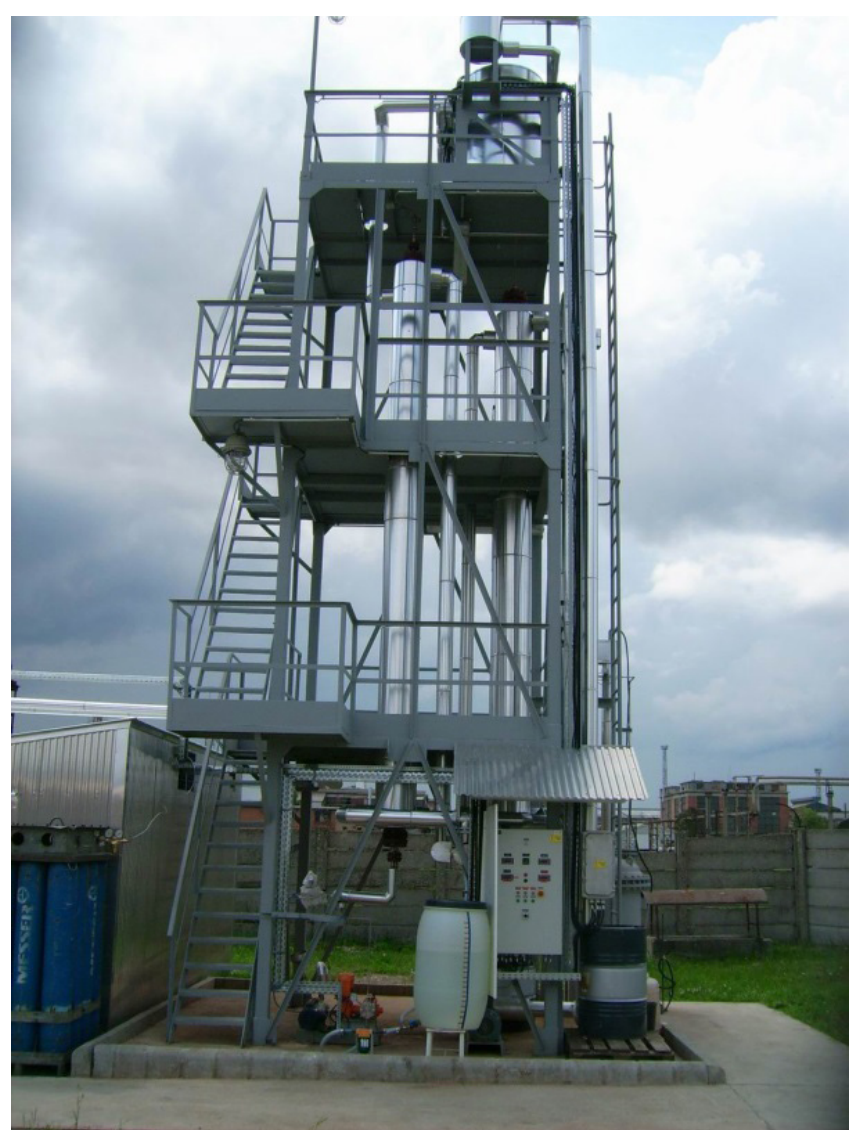

Fig. 9 Photo of the wet oxidation plant at Geosan
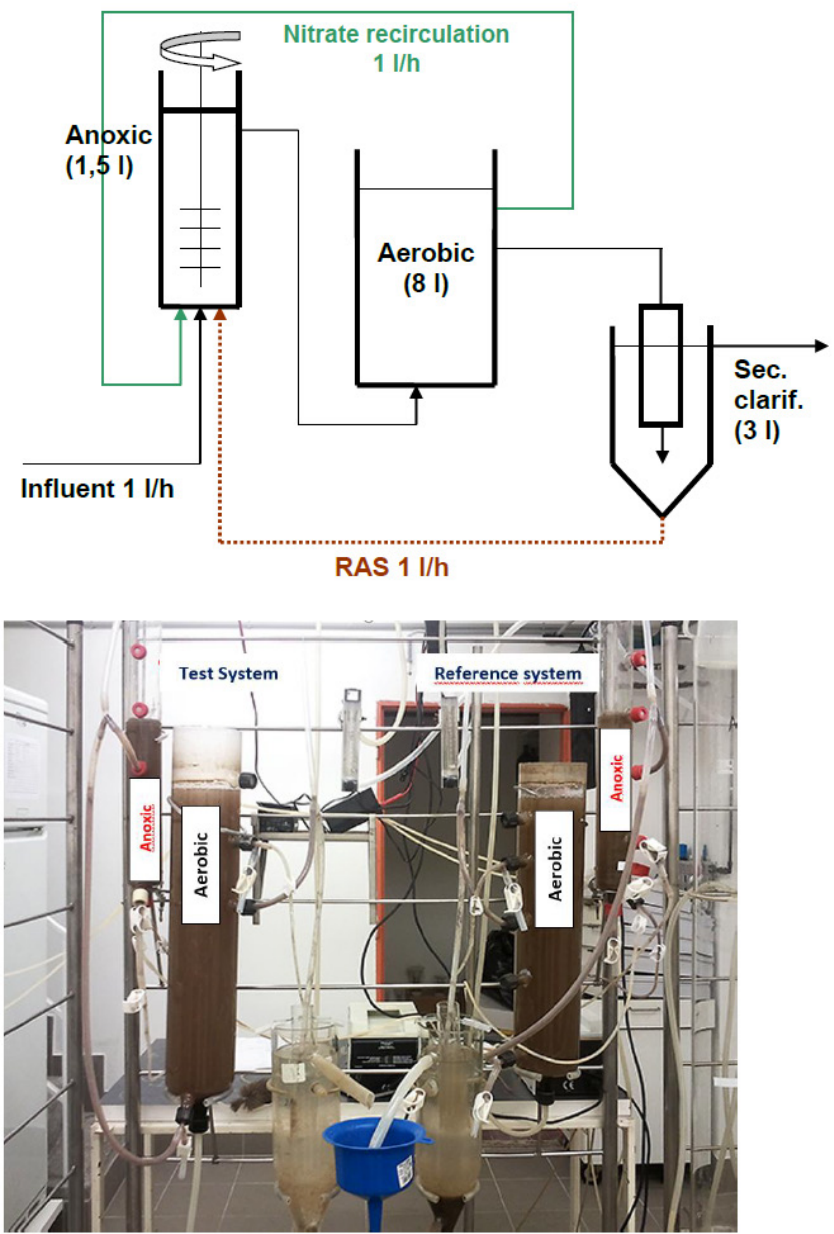

Fig. 10 Scheme and picture of the laboratory activated sludge treatment system 


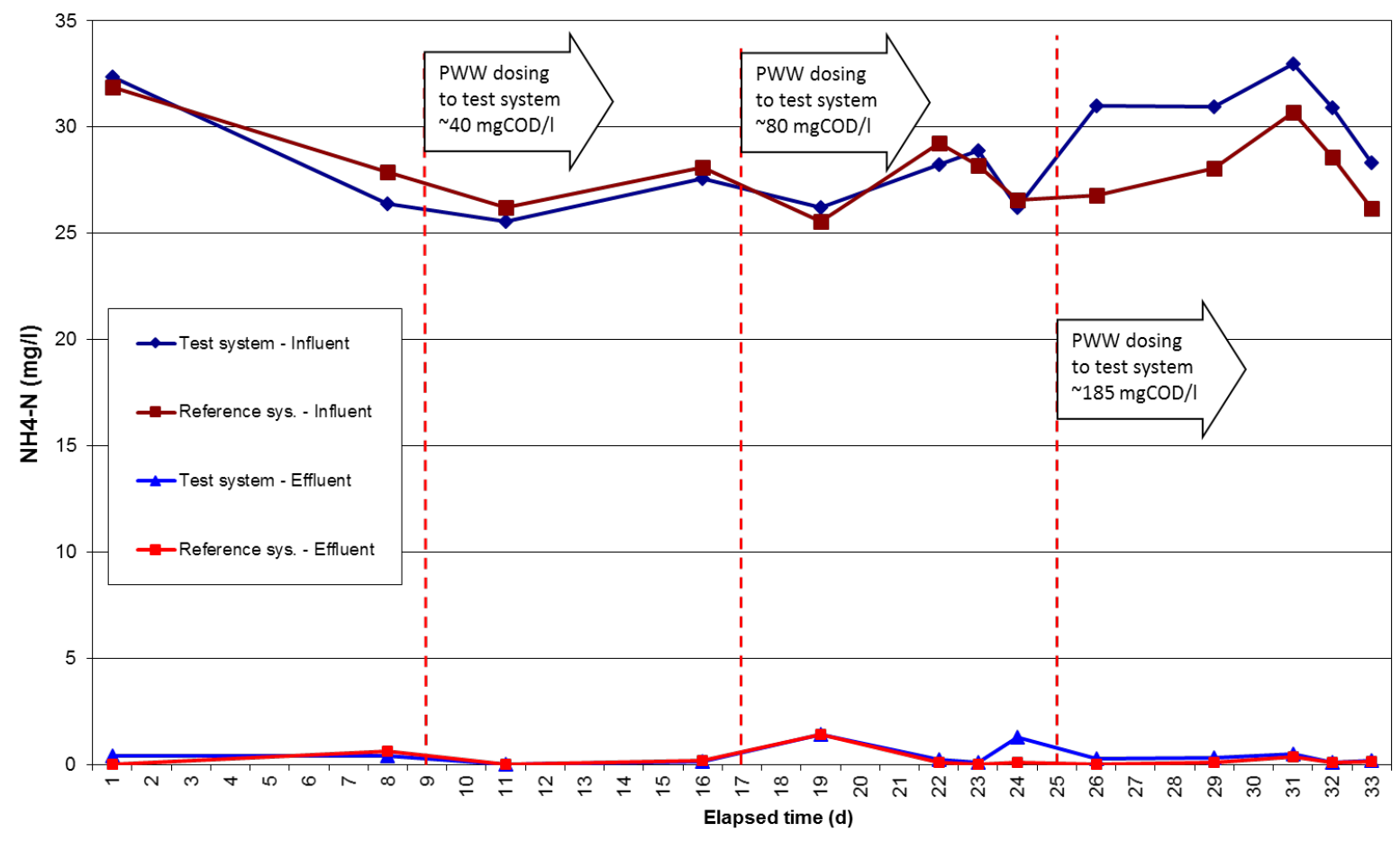

A)

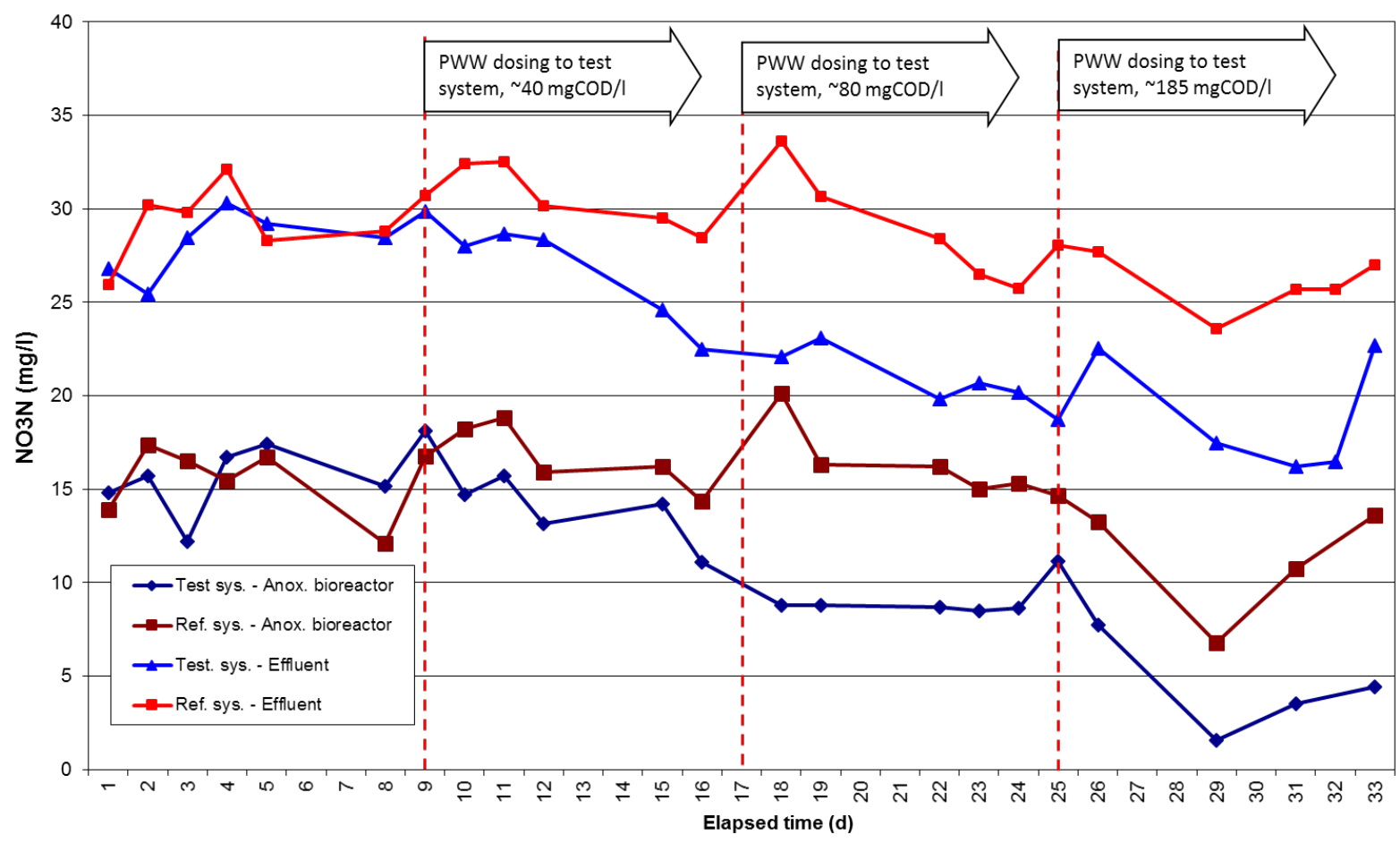

B)

Fig. 11 Effluent quality of the continuous-flow activated sludge experiment A) $\mathrm{NH}_{4}-\mathrm{N}$ concentration in the effluent of the test and reference systems, B) $\mathrm{NO}_{3}-\mathrm{N}$ concentration in the anoxic reactors and in the effluents of the test and reference systems 
$\mathrm{NO}_{3}-\mathrm{N}$ concentration considerably decreased compared to the reference system, as the dosed PWW was utilized as additional carbon source for the denitrification in the anoxic reactor (see Fig. 11B). During the experiment no raise has been observed in the effluent COD concentration of the test system indicating that organic pollutants of the dosed PWW biodegraded appropriately in the system. According to calculations based on the results of the batch and continuous experiments $1 \mathrm{~m}^{3} \mathrm{PWW}$ of this type may replace $0.33 \mathrm{~m}^{3}$ methanol as carbon source.

Thereafter similar long term experiment was carried out successfully at Geosan plant in a system which was approximately 10 times higher volume. Similarly to the previous experiment the PWW could be used as carbon source and its COD content was appropriately eliminated.

AOP treatments of emergent pollutants and microorganisms in the WWTP effluent.

\section{UV-Photo-Fenton reaction}

The removal of 22 selected pollutants was tested in an effluent from a municipal WWTP at pilot scale by researchers of EPFL. The reactor of 371 volume was equipped with five low pressure mercury lamps emitting at $254 \mathrm{~nm}\left(\mathrm{UV}_{254}\right)$ (Fig. 12). The 22 micro-pollutants were the following: 15 pharmaceuticals, 2 X-Ray contrast agents, 1 corrosion inhibitor and 4 biocides/pesticides. Five of these 22 compounds as indicative substances were selected upon the proposal of the Swiss Federal Office for the Environment (FOEN): carbamazepine, diclofenac, sulfamethoxazole, benzotriazole and mecoprop. Three treatment modes were tested: UV254 light alone, $\mathrm{UV}_{254}$ $+\mathrm{H}_{2} \mathrm{O}_{2}$ and $\mathrm{UV}_{254}+\mathrm{H}_{2} \mathrm{O}_{2}+\mathrm{Fe}^{3+}$. The effluent of the municipal WWTP already contained iron with an average concentration of $1.6 \mathrm{mg} / \mathrm{l}$. Its original $\mathrm{pH}$ was not modified and remained between 6 and 7 . The parameter ranges were: wastewater flow rate $2-14 \mathrm{~m}^{3} / \mathrm{h}, \mathrm{H}_{2} \mathrm{O}_{2}$ concentration $20-50 \mathrm{mg} / \mathrm{l}$ and $\mathrm{Fe}$ (III) concentration $0-4 \mathrm{mg} / \mathrm{l}$.

The degradation was greater than $80 \%$ even with low residence times only applying UV light and $\mathrm{H}_{2} \mathrm{O}_{2}$. The degradation threshold of $80 \%$ elimination of the five indicative substances after the treatment could be achieved with residence times from 10 to $67 \mathrm{~s}$. The maximum required $\mathrm{H}_{2} \mathrm{O}_{2}$ dose never exceeded $50 \mathrm{mg} / \mathrm{l}$. The economic study of the system was also carried out to evaluate operation costs. The most economical setting was $14 \mathrm{~m}^{3} / \mathrm{h}$ (residence time: $10 \mathrm{~s}$ ) wastewater feed, with a $\mathrm{H}_{2} \mathrm{O}_{2}$ dose of $50 \mathrm{mg} / \mathrm{l}$. An important observation was that adding of iron into the reactor did not improve the conversion rate [22].

\section{Irradiation with high energy electron beam}

The only available device for high energy electron beam irradiation is a TESLA Linac of laboratory scale. The degradation of different water pollutants was tested with this apparatus in batch reactions and rate constants determined (see at laboratory experiments). The application of this technology is in practice in Korea where EB Tech Company produces and uses pilot and industrial scale electron accelerators, among others for wastewater treatment [23]. In order to demonstrate the suitability of the electron irradiation for the treatment of WWTP's effluents within our project, a continuously operated device has been built (Fig. 13) and operated.

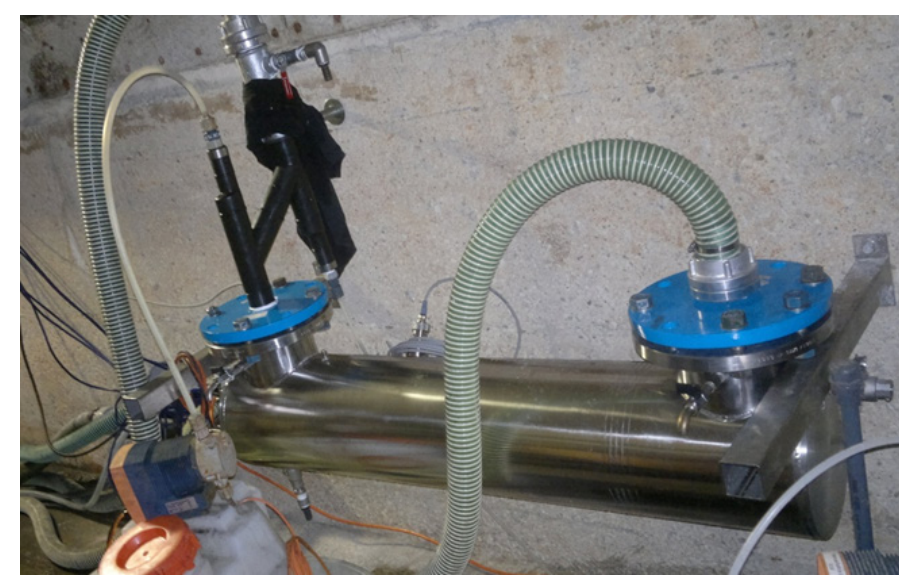

Fig. 12 Pilot scale reactor for UV Photo-Fenton treatment of WWTP effluent

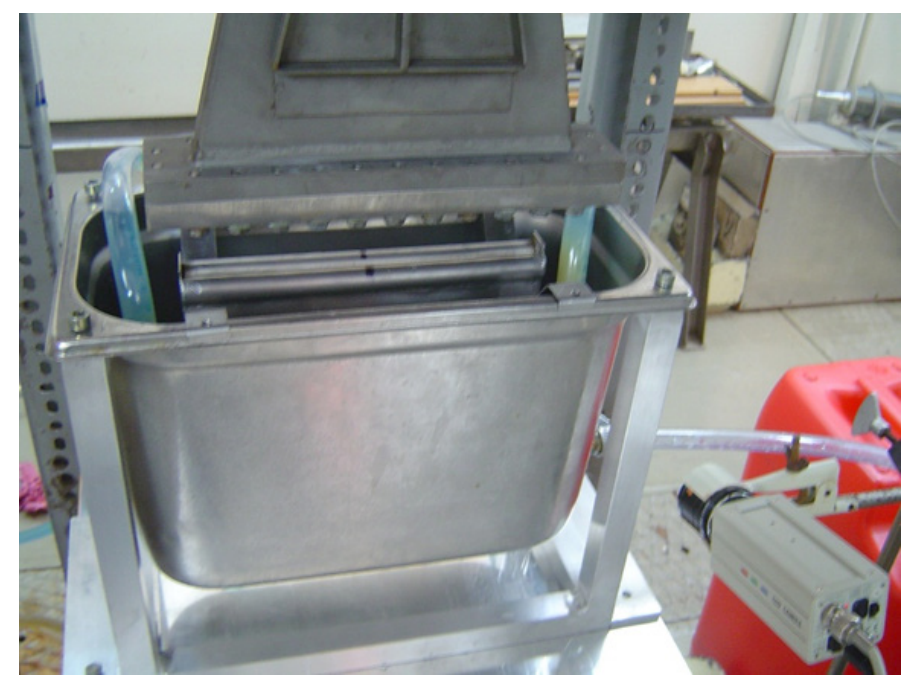

Fig. 13 Continuous device for electron beam irradiation of a polluted water

The polluted water of pink color containing a dyestuff (trivial name: Apollofix-Red SF-28, concentration: $0.1 \mathrm{mmol} / \mathrm{l}$ ) was fed into the tank placed beneath the window of the electron accelerator and was circulated through a film forming slot, and was irradiated in a 1-2 mm thick film. The effluent of the device became colorless, showing the efficiency of the treatment.

The Korean experiences and this demonstration experiment (Fig. 13) proved that high energy irradiation with electron beam can become a commercial method for the post-treatment of WWTP effluents eliminating emergent pollutants and microorganisms. 
Table 3 Basic data of design

\begin{tabular}{|c|c|c|c|}
\hline $\begin{array}{l}\text { Treated effluents and } \\
\text { processes }\end{array}$ & Quantities and sizes & Parameters & $\begin{array}{l}\text { Process characteristics } \\
\text { given here or in the respective chapters }\end{array}$ \\
\hline $\begin{array}{l}\text { Process wastewater } \\
\text { PWW }\end{array}$ & $\begin{array}{l}\text { Amount } 30.000 \mathrm{~m}^{3} / \mathrm{y} \\
100-150 \mathrm{~m}^{3} / \mathrm{d}\end{array}$ & $\begin{array}{l}\text { Characteristics range } \\
\text { COD } 15-700 \mathrm{~g} / 1 \text { TOC } 8-200 \mathrm{~g} / 1 \\
\text { BOD 2-700 g/1 } \\
\text { pH 1-14 }\end{array}$ & $\begin{array}{l}\text { Ratio of PWW's } \\
\text { for distillation } \sim 35 \% \\
\text { for wet oxidation } \sim 20 \%\end{array}$ \\
\hline $\begin{array}{l}\text { Volume of receiving } \\
\text { storage tanks }\end{array}$ & $\begin{array}{l}\text { for biodegradation } \\
\text { for distillation } \\
\text { toxic, for wet oxidation }\end{array}$ & $\begin{array}{l}500 \mathrm{~m}^{3} \\
300 \mathrm{~m}^{3} \\
200 \mathrm{~m}^{3}\end{array}$ & \\
\hline $\begin{array}{l}\text { PWW's for direct } \\
\text { biodegradation }\end{array}$ & $\begin{array}{l}\text { Amount } 13-25.000 \mathrm{~m}^{3} / \mathrm{y} \\
45-100 \mathrm{~m}^{3} / \mathrm{d}\end{array}$ & $\begin{array}{l}\text { Characteristics range COD } \\
15-200 \mathrm{~g} / 1 \\
\text { TOC } 8-100 \mathrm{~g} / 1 \\
\text { BOD } 15-200 \mathrm{~g} / 1\end{array}$ & $\begin{array}{l}\text { Dilution } 500-1000 \mathrm{x} \\
\text { Mixing method: into influent pump or static mixer }\end{array}$ \\
\hline PWW's for distillation & $\begin{array}{l}\text { Amount } 10.000 \mathrm{~m}^{3} / \mathrm{y} \\
35-50 \mathrm{~m}^{3} / \mathrm{d}, 10-15 \mathrm{~m}^{3} / \mathrm{d} \text { for AOX } \\
\text { rem., } 25-45 \mathrm{~m}^{3} / \mathrm{d} \text { for solvent dist. } \\
\text { Storage tanks for distilled sol- } \\
\text { vents: } 3 \times 25 \mathrm{~m}^{3}\end{array}$ & $\begin{array}{l}\text { Solvents: ethanol, methanol, } \\
\text { toluene, ethyl acetate, dichloro- } \\
\text { methane, methyl isobutyl } \\
\text { ketone, conc. } 1.5-60 \%\end{array}$ & $\begin{array}{l}\text { Column parameters for a stripping column for AOX } \\
\text { removal and a distillation column for volatile solvent } \\
\text { removal }\end{array}$ \\
\hline $\begin{array}{l}\text { PWW's for wet } \\
\text { oxidation }\end{array}$ & $\begin{array}{l}\text { Amount } 6.000 \mathrm{~m}^{3} / \mathrm{y} \\
20-30 \mathrm{~m}^{3} / \mathrm{d}\end{array}$ & Parameters: $230^{\circ} \mathrm{C}, 50$ bar & $\begin{array}{l}20-30 \mathrm{~m}^{3} / \mathrm{d} \text {, with COD conversion } \sim 20-25 \% \\
\text { two reactors, one loop and one bubble column } \\
\text { reactor }\end{array}$ \\
\hline $\begin{array}{l}\text { Activated sludge } \\
\text { treatment }\end{array}$ & $\begin{array}{l}\text { Amount of domestic wastewater } \\
100.000 \mathrm{~m}^{3} / \mathrm{d} \\
\text { Possible dilution of PWW's } \\
500-1000 \mathrm{x}\end{array}$ & $\begin{array}{l}\text { Characteristics range } \\
\text { COD } 400-800 \mathrm{mg} / 1 \\
\text { influent BOD5/NH4-N ratio 4-8 } \\
\mathrm{NH} 4-\mathrm{N} \text { concentrations } 40-60 \\
\mathrm{mg} / 1\end{array}$ & $\begin{array}{l}\text { Volume of basins } \\
\text { Sludge age } \\
\text { Sludge amount } \\
\text { Excess sludge from PWW } \\
\text { Electrical energy, steam and chemicals consumption }\end{array}$ \\
\hline $\begin{array}{l}\text { Treatment of effluent of } \\
\text { biological treatment, }\end{array}$ & $\begin{array}{l}\text { Amount } 100.000 \mathrm{~m}^{3} / \mathrm{d} \text { disin- } \\
\text { fection and decomposition of } \\
\text { emergent pollutants }\end{array}$ & $\begin{array}{l}\text { Photo-Fenton } \\
\text { Irradiation }\end{array}$ & Type of continuous reactors and their volume \\
\hline
\end{tabular}
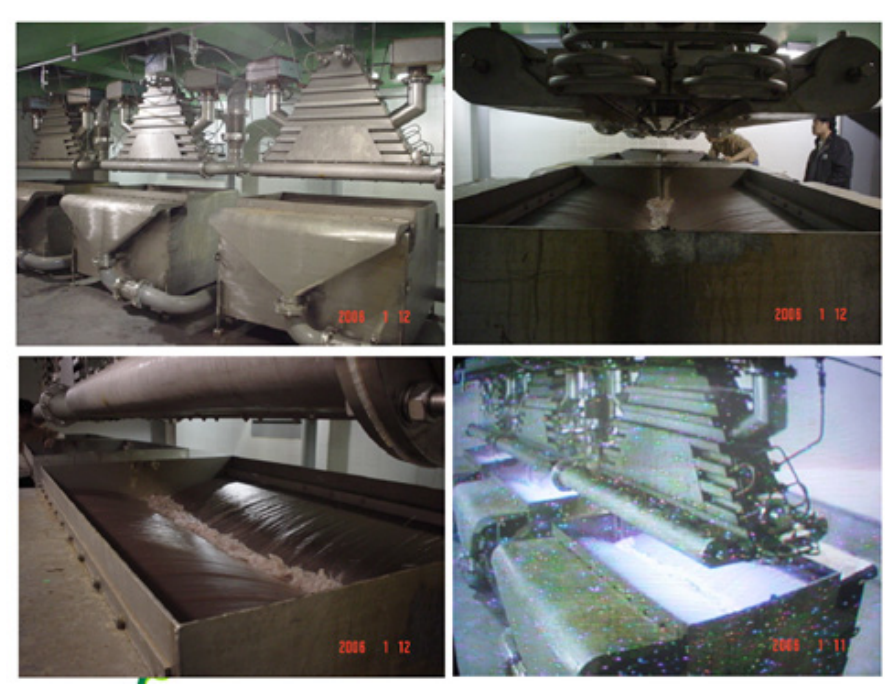

Fig. 14 Photos about the electron beam irradiation device
Design and evaluation of a complex treatment facility for $P W W$ s of pharmaceutical production attached to a $100000 \mathrm{~m}^{3} /$ day capacity municipal WWTP

In Table 3 the starting conditions of the design of a treatment plant are summarized. These input data are valid for the situation in Budapest, regarding the North-Pest WWTP and the three pharmaceutical companies located here and have active agent production activity. The scheme of the whole plant is depicted on Fig. 15. A flexible rectification column for the removal of VOC has been designed. In Table 4 the extreme cases are characterized.

The column is heat integrated, the energy saving is around $100 \mathrm{~kW}$ for both mixtures.

It is necessary to mention that the toluene-water separation could be solved in much simpler way, that is, smaller column in diameter and packing height but in such case a second column would be necessary. It has to be also mentioned that in 
Table 4 Typical data of the VOC removal column

\begin{tabular}{lll}
\hline & Ethanol-water & Toluene-water \\
\hline Reflux ratio & 2 & 50 \\
D/F ratio & 0.6 & 0.0092 \\
Vapor rate in the top & 2925 & 765 \\
of the column & $0.6 \sqrt{\mathrm{Pa}}$ & $2.2 \sqrt{\mathrm{Pa}}$ \\
F-factor, selected for design & $0.65 \mathrm{~m}$ & $0.65 \mathrm{~m}$ \\
$\begin{array}{l}\text { Diameter of the column } \\
\text { Number of theoretical plates }\end{array}$ & 20 & 20 \\
Feed tray location & $10 \mathrm{th}$ & $10 \mathrm{th}$ \\
Height of the column packing & $4 \mathrm{~m}$ & $4 \mathrm{~m}$ \\
Heat load of the reboiler & $\sim 1270 \mathrm{~kW}$ & $\sim 420 \mathrm{~kW}$ \\
\hline
\end{tabular}

the cases of the removal of compounds with limited solubility in water, phase separation is also possible depending on the composition of the distillate.

In the industry the single column version is preferred and they do not want to install two or more columns for the same problem, that is, the treatment of process wastewaters removing the VOC.

In the wet oxidation step the polluted water stream after dilution and basification can be between $40-100 \mathrm{~m}^{3} / \mathrm{d}$, the reactor output $2-5 \mathrm{~m}^{3} / \mathrm{h}$. On the basis of previous experiences we prefer a two stage reactor system, the first unit can be modelled by a CISTR (continuous ideally stirred tank reactor) or a fast circulation loop reactor (identical in calculation method), the second unit can be modelled by a tubular plug flow, bubble column reactor (PFR) (Fig. 16).

The calculated extremes for the loop reactor are the following: smallest reactor volume is 5001 , the largest 360001 . With the values in the middle of the above ranges $(4000 \mathrm{l} / \mathrm{h}, 30 \mathrm{~g} / \mathrm{l}$, $10 \mathrm{~g} / 1 \mathrm{x}$ hour and $10 \% \mathrm{COD}$ conversion) the reactor volume is $1200 \mathrm{l}$, which is a reasonable size. The recirculation in the loop, composed of two column reactors of 6001 each, has to be at least $20000 \mathrm{l} / \mathrm{h}$, that is to say $330 \mathrm{l} / \mathrm{min}$. In the case of the plug flow type, bubble column reactor the calculated extremes are the following: smallest reactor volume is 32 , the largest 244501 . Taking the values in the middle of the above ranges $(4000 \mathrm{l} / \mathrm{h}, 25$ $\mathrm{g} / 1,10 \mathrm{~g} /(1 \mathrm{x}$ hour $)$ and $8 \% \mathrm{COD}$ conversion $)$ the reactor volume is 8341 , which is a reasonable volume. A bubble column reactor of $12 \mathrm{~m}$ height and with $0.3 \mathrm{~m}$ diameter corresponds this size.

The main unit of the treatment facility is the activated sludge wastewater treatment system, this is like one of the plants of BSW, an activated sludge treatment plant working with pre-denitrification.

Further units at the plant: influent sedimentation, precipitation of phosphorous with $\mathrm{FeCl}_{3}$, the anaerobic digestion of excess sludge producing biogas, its conversion to electricity and heat, sludge dewatering.
The original biodegradable and the pretreated PWW can be introduced into this plant together with the influent domestic wastewater, so being diluted in the required ratio up front of its biological degradation.

Typical concentration parameters of the influent domestic wastewaters in Hungary:

Total COD: 400-800 mg/l, NH4-N: 40-60 mg/l, TKN (total Kjeldahl nitrogen): 45-85 mg/1, Total P: 5-15 mg/l

Typical design and operating parameters in this case study:

Influent flow rate: $100000 \mathrm{~m}^{3} / \mathrm{d}$, HRT: 0,3-0,6 d hydraulic retention time, SRT: 5-15 d Solids Retention Time. Reactor volume (sum): 30000 - $60000 \mathrm{~m}^{3}$ (typical anoxic/aerobic volume ratio: 0.1-0.3). RAS: $100000-150000 \mathrm{~m}^{3} / \mathrm{d}$ (recirculation ratio $1-1.5$ ) return activated sludge.

Nitrate recirculation: $100000-400000 \mathrm{~m}^{3} / \mathrm{d}$ (recirculation ratio 1-4). Excess sludge (with typical influent concentrations): $30000-50000 \mathrm{~kg} / \mathrm{d}$.

Characteristic values of effluent in $\mathrm{mg} / \mathrm{l}$ :

COD 32, $\mathrm{BOD}_{5}<10, \mathrm{pH} 7,7$, TSS (total suspended solids) 8 , TN (total nitrogen 10.7, $\mathrm{NH}_{4}-\mathrm{N} 4.27$, TP (total phosphorous) 1.96. Further parameters for design and evaluation procedure: Excess sludge from PWW addition: 5-7.000 kg/day. Electric energy consumption of the whole plant: 65-70.000 kWh/day, currently this amount is covered in $60-70 \%$ from own source, from own biogas with gas-engines driven generators. The sludge excess from adding PWW can increase the biogas production and so the ratio of own generated electricity. The two boilers, producing hot water for the whole plant fire biogas originating from the own plant. Consumption of chemicals: iron(III) chloride solution ( $40 \%$ conc.) 9000 1/day.

Post-treatment for degradation of emergent pollutants and disinfection

Irradiation with high energy electron beam

For the post-treatment two methods were taken into account: the electron beam irradiation and the photo-Fenton reaction. The former was implemented in industrial scale by a SouthKorean firm (EB TECH Co.) recently [23]. MTA EK has a cooperation with them, in the frame of this cooperation was the presentation material received (see details below) and used with their permission.

In this process the water, containing small amount of pollutants and microbes, flows into the irradiator in the form of a relatively thin film (Fig. 14). This ensures that the total cross section of the incoming spout, that is to say the total water amount gets the necessary radiation dose. With respect to its feasibility, the investment costs are nowadays still rather high, but they will decrease with time due to the spread of this technology. The EB TECH offers a mobile experimental accelerator also, which can be used in pilot scale for determining the necessary dose for the desirable degree of degradation and disinfection. 


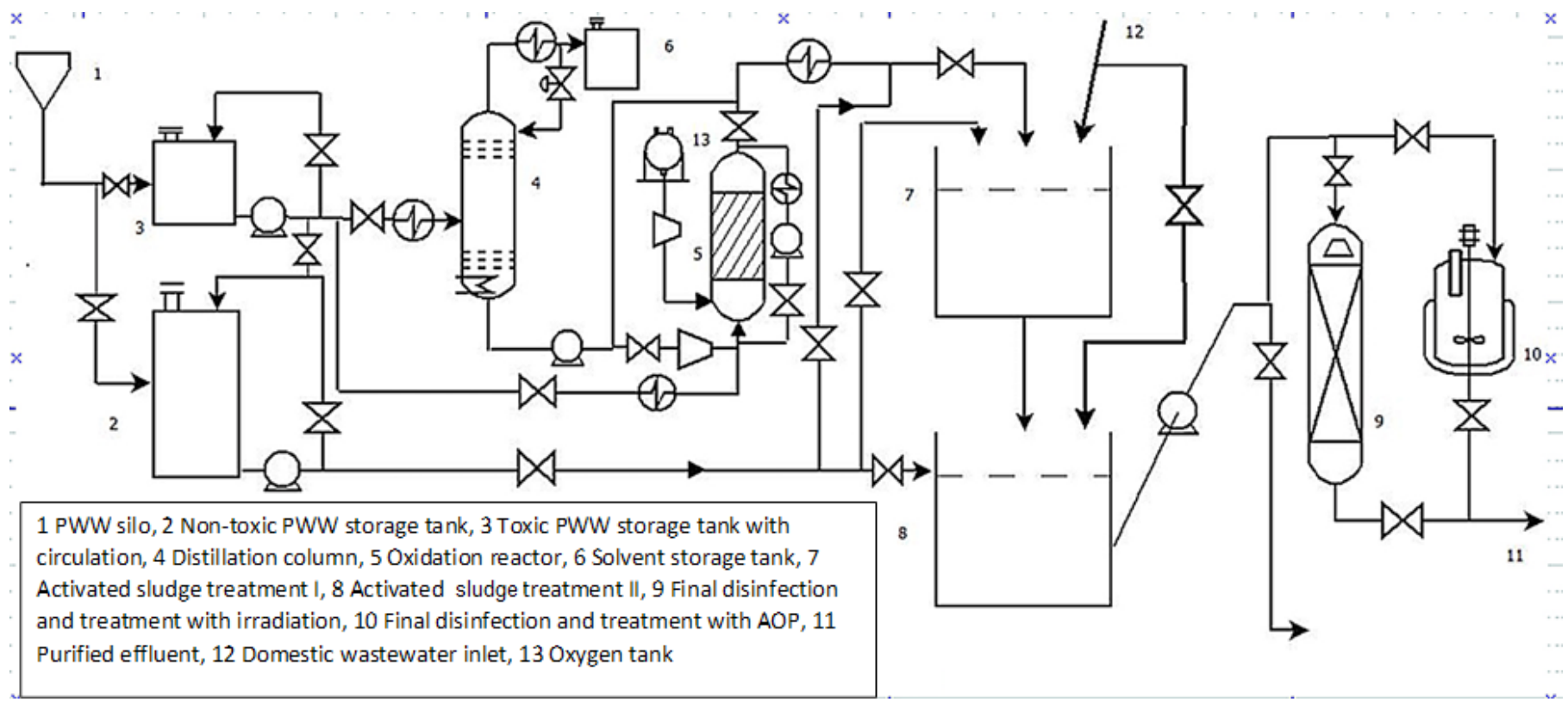

Fig. 15 Scheme of the complex process wastewater treatment plant

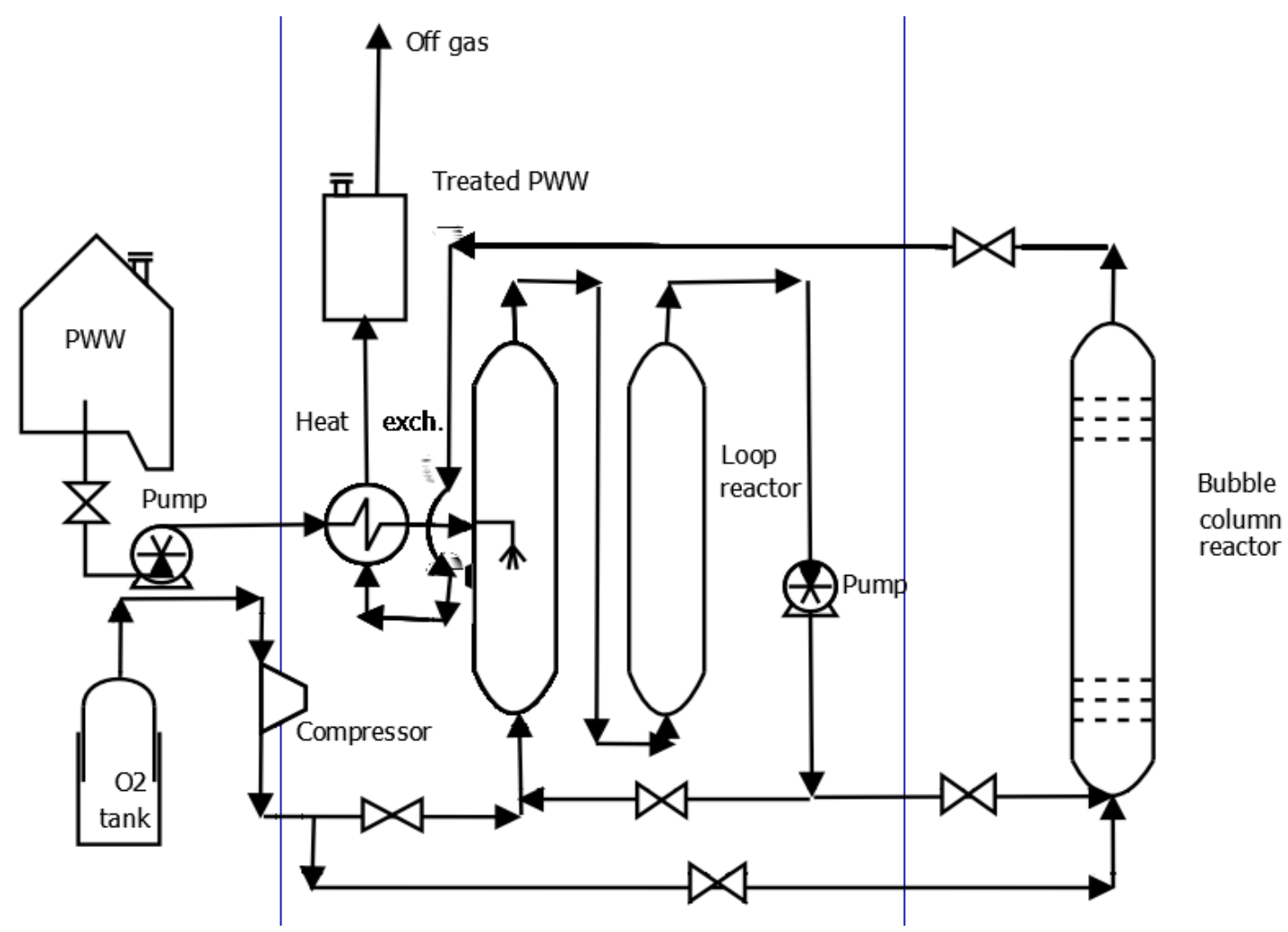

Fig. 16 Scheme of the wet oxidation plant

The $400 \mathrm{~kW}$ irradiation device can fulfil the requirements of our $100000 \mathrm{~m}^{3} /$ day plant, we extrapolated its capacity lowering the necessary dose from 2 to $0.2 \mathrm{kGy}$. According to preliminary experiments this dose is sufficient for disinfection and degradation of emergent pollutants.

\section{UV Photo Fenton treatment}

The WWTPs in their present form, are not designed to apply effective treatment, targeting the permanent removal of emergent pollutants. Therefore, the need to integrate technologies that offer effective abatement of the target compounds of small concentration is gaining more attention. The Advanced Oxidation Processes (AOPs), which focus in the massive production of the highly oxidizing hydroxyl radical, offer the window of opportunity towards the implementation of control strategies. Under the scopes of the present project, a pilot plant has been installed in the wastewater treatment plant of Vidy, Lausanne, using the $\mathrm{UV} / \mathrm{H}_{2} \mathrm{O}_{2} \mathrm{AOP}$ as a method of treating secondary effluent [20]. (Fig. 12). 
The main result of this study was to establish a known disinfection technology into a different target; the abatement of $80 \%$ of the emerging pollutants was attained. An optimization towards the residence time and the amount of applied $\mathrm{H}_{2} \mathrm{O}_{2}$ was carried out.

The study of the proposed $\mathrm{UV} / \mathrm{H}_{2} \mathrm{O}_{2}$ solution was based on the findings of the pilot scale plant in Vidy, Lausanne, and the designer recommendations of Wedeco.

An initial approach suggests that for $8 \mathrm{mg} / \mathrm{l}$ TSS in effluent of WWTP, a $60-70 \%$ UV transmittance will be regarded. Although the required UV irradiance is $70 \mathrm{~W} / \mathrm{m}^{2}$ (according to the pilot scale plant), the constructors recommend a minimum dose of $300 \mathrm{~W} / \mathrm{m}^{2}$.

In this case, in order to treat effectively the inflow of 100.000 $\mathrm{m}^{3} /$ day, 3 modules of 8 lamps $=24$ lamps per bank should be employed and each of the 2 recommended channels should facilitate 3 banks (Fig. 17).

The $\mathrm{UV} / \mathrm{H}_{2} \mathrm{O}_{2}$ AOP is reliable, flexible, can be adapted to different quality effluents, and finally has high modification potentials. With respect to disinfection the benefits of $\mathrm{H}_{2} \mathrm{O}_{2}$ addition could eliminate the microorganisms; so far, there is no known defense mechanism against external radicals attack on microorganisms. Furthermore, the presence of iron and the residual $\mathrm{H}_{2} \mathrm{O}_{2}$, will induce a continuing Fenton reaction, which will suppress the regrowth of microorganisms, the Achilles' heel of UV disinfection.

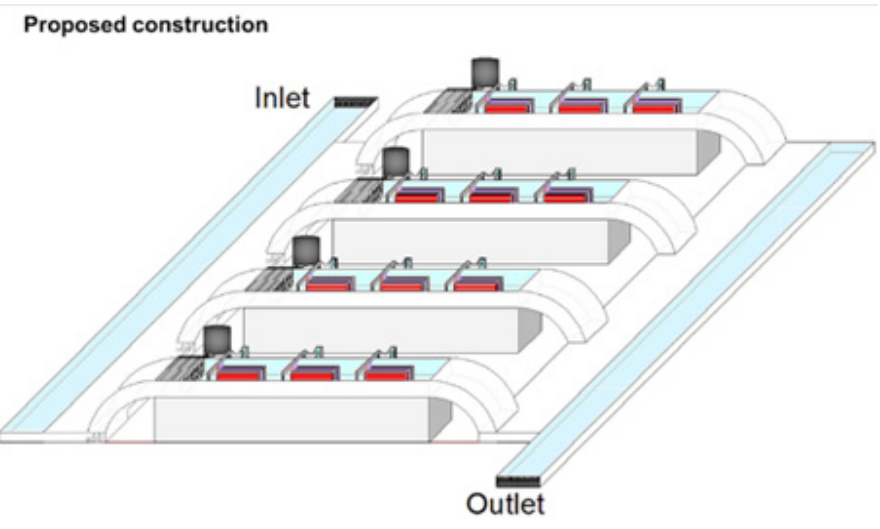

Fig. 17 Design overview of the proposed UV Photo Fenton treatment solution

Environmental evaluation of the complex treatment facility for the disposal and utilization of process wastewaters of the pharmaceutical industry

In the framework of the Swiss-Hungarian project a complex process wastewater facility is elaborated and designed in order to treat and utilize organic carbon content of pharmaceutical process- and wastewaters. Wastewater treatment is an environmentally-oriented industrial activity at which the up-to-date engineering practice demands the environmental evaluation and analysis how the industrial activity effects the environment.
At environmentally-oriented analyses, it is not sufficient to analyse environmental effects just on the site but secondary effects (i.e. environmental effects of electricity production in the power plant) has to be involved in the analysis, too. Life cycle assessment (LCA) is widely accepted tool in the chemical industry to assess environmental impacts of industrial activities which enables the environmentally-oriented ranking and analysis.

In this work, environmental performance of the proposed complex wastewater treatment facility is determined considering both direct and indirect environmental effects of operation. Data of operation and design has been elaborated in former studies within the project.

It is important to understand that the different units of the proposed complex wastewater treatment plant have different functions, e.g. those wastewaters which have to be treated by distillation in order to eliminate high solvent concentration cannot be treated as-it-is by the activated sludge unit. Therefore, the different units do not compete for the better environmental ranking since none of the units have the same function.

Environmental performance of the proposed wastewater treatment plant is determined by LCA, keeping in mind that the units of the proposed plant cannot replace each other's function. Environmental impacts are expressed by the aggregated (single) score impact assessment method: IMPACT2002+, damage indicators for COD is added manually to the original method.

Analysis of the specific environmental performance data (related to $1000 \mathrm{~m}^{3}$ of treated wastewater) shows that those units which are designed for processing high quantity wastewaters (activated sludge, disinfection units) have significant less environmental expenditures than those which are designed for low quantity, special wastewater streams (distillation, wet air oxidation units). Treatment of ethanol-like wastewaters is an exception: this method has more positive than negative environmental effect. The highest environmental savings (reduction in pollutant concentration and its environmental effects) can be achieved by the activated sludge unit.

In the proposed realistic operational state of the wastewater treatment facility, environmental expenditures of the different units are similar; there is no really best or worse unit, wet air oxidation has the lowest environmental expenditure; however, this unit has low benefits, too. Activated sludge unit and VOC COD removal units provide the highest environmental savings.

Environmental impacts of conventional (biological treatment and incineration of the special process waters) wastewater treatment is compared to those of the proposed wastewater treatment facility, and untreated release to nature (Fig. 18). The comparison shows that the worse option is the conventional method including incineration; the proposed wastewater treatment activity has lower environmental impacts than those of the untreated release. 


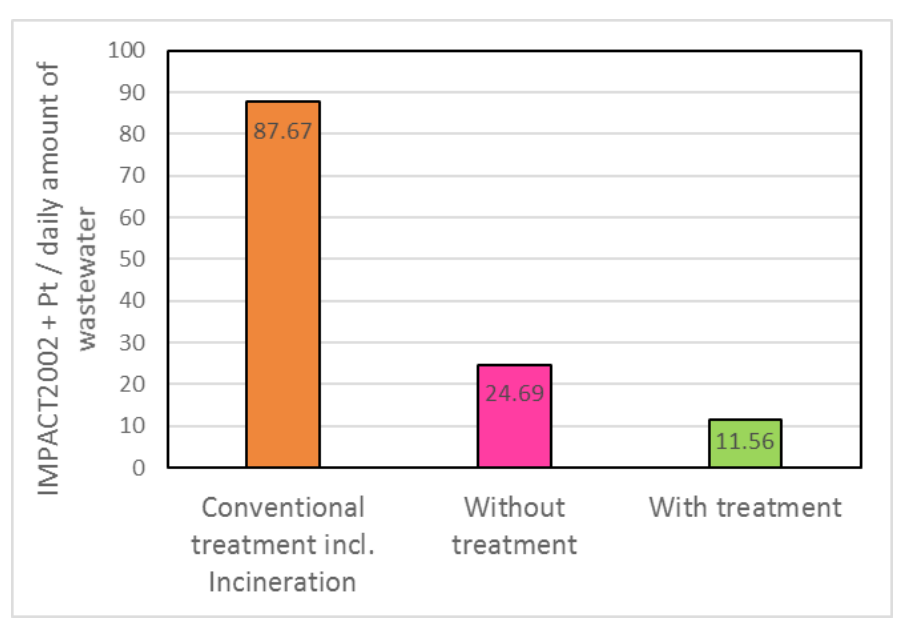

Fig. 18 The environmental impact of liquid waste treatment methods

\section{Conclusions}

The original suggestion of Professor Andrea Jobbágy has been verified, that the high organic and water containing liquid wastes of pharmaceutical origin can be disposed of and utilized in a WWTP after mixing with high ratio municipal wastewater in an activated sludge treatment. The majority of these wastes can be fed directly into the WWTP, the minority has to be pretreated with distillation and/or wet oxidation for the removal of the toxic and non-biodegradable components. Thereafter this pre-treated portion can be introduced into the activated sludge treatment also and serve as carbon source for denitrification. The effluent of the WWTP can be treated by AOP methods, UV Photo-Fenton or high energy electron beam irradiation. The after-treatment serves for the removal of the emergent pollutants and disinfection also. The complex treatment facility coupled with a $100000 \mathrm{~m}^{3} /$ day capacity WWTP has been designed and evaluated by life cycle analysis.

\section{Acknowledgement}

The authors acknowledge the financial support of NKTH Jedlik project, title VeHuHa and Swiss-Hungarian Cooperation Program SH7/2/14 Pharmawater project.

\section{References}

[1] Mizsey, P. "Waste reduction in the chemical industry: a two level problem." Journal of Hazardous Materials. 37(1), pp. 1-13. 1994. https://doi.org/10.1016/0304-3894(94)85028-3

[2] Dang, J. S., Harvey, D. M., Jobbagy, A., Grady, Jr. C. L. "Evaluation of biodegradation kinetics with respirometric data." Research Journal of the Water Pollution Control Federation. 61(11-12), pp. 1711-1721. 1989. URL: http://www.jstor.org/stable/41480395

[3] Smets, B. F., Jobbágy, A., Cowan, R. M., Grady, Jr, C. L. "Evaluation of respirometric data: Identification of features that preclude data fitting with existing kinetic expressions." Ecotoxicology and Environmental Safety. 33(1), pp. 88-99. 1996.

[4] Hosseini, A. M., Bakos, V., Jobbágy, A., Tardy, G., Mizsey, P., Makó, M., Tungler, A. "Co-treatment and utilisation of liquid pharmaceutical wastes." Periodica Polytechnica Chemical Engineering. 55(1), pp. 3-10. 2011. https://doi.org/10.3311/pp.ch.2011-1.01
[5] Földváry, C. M., Wojnárovits, L. "The effect of high-energy radiation on aqueous solution of Acid Red 1 textile dye." Radiation Physics and Chemistry. 76(8-9), pp. 1485-1488. 2007.

https://doi.org/10.1016/j.radphyschem.2007.02.057

[6] Comninellis, C., Pulgarin, C. "Electrochemical oxidation of phenol for wastewater treatment using $\mathrm{SnO} 2$, anodes." Journal of Applied Electrochemistry. 23(2), pp. 108-112. 1993.

https://doi.org/10.1007/BF00246946

[7] Comninellis, C., Pulgarin, C. "Anodic oxidation of phenol for waste water treatment." Journal of Applied Electrochemistry. 21(8), pp. 703-708. 1991. https://doi.org/10.1007/BF01034049

[8] Sarria, V., Parra, S., Adler, N., Péringer, P., Benitez, N., Pulgarin, C. "Recent developments in the coupling of photoassisted and aerobic biological processes for the treatment of biorecalcitrant compounds." Catalysis Today. 76(2-4), pp. 301-315. 2002.

https://doi.org/10.1016/S0920-5861(02)00228-6

[9] Tardy, G. M., Bakos, V., Jobbágy, A. "Conditions and technologies of biological wastewater treatment in Hungary." Water Science \& Technology. 65(9), pp. 1676-1683. 2012.

https://doi.org/10.2166/wst.2012.062

[10] Tardy, G., Jobbágy, A. "Enhancing activated sludge nitrification through seeding from a downstream nitrifying fixed-film reactor." Periodica Polytechnica Chemical Engineering. 51(1), pp. 33-37. 2007. https://doi.org/10.3311/pp.ch.2007-1.06

[11] Monod, J. "The growth of bacterial cultures." Annual Review of Microbiology. 3, pp. 371-394. 1949.

https://doi.org/10.1146/annurev.mi.03.100149.002103

[12] Andrews, J. F. "A mathematical model for the continuous culture of microorganisms utilizing inhibitory substrates." Biotechnology and Bioengineering. 10(6), pp. 707-723. 1968. https://doi.org/10.1002/bit.260100602

[13] Yetim, T., Tekin, T. "A Kinetic Study on photocatalytic and Sonophotocatalytic Degradation of Textile Dyes." Periodica Polytechnica Chemical Engineering. 61(2), pp. 102-108. 2017. https://doi.org/10.3311/PPch.8535

[14] Hosseini, A. M., Tungler, A., Bakos, V. "Wet oxidation properties of process waste waters of fine chemical and pharmaceutical origin." Reaction Kinetics, Mechanisms and Catalysis. 103(2), pp. 251-260. 2011. https://doi.org/10.1007/s11144-011-0315-2

[15] Jobbágy, A., Simon, J., Plósz, B. "The impact of oxygen penetration on the estimation of denitrification rates in anoxic processes." Water Research. 34(9), pp. 2606-2609. 2000. https://oi.org/10.1016/S0043-1354(00)00013-0

[16] Hosseini, A.M., Tungler, A., Schay, Z., Szabó, S., Kristóf, J., Széles, É., Szentmiklósi, L. "Comparison of precious metal oxide/titanium monolith catalysts in wet oxidation of wastewaters." Applied Catalysis B: Environmental. 127 , pp. 99-104. 2012 https://doi.org/10.1016/j.apcatb.2012.08.004

[17] Koczka, K., Mizsey, P. "New area for distillation: wastewater treatment." Periodica Polytechnica Chemical Engineering. 54(1), pp. 41-45. 2010. https://doi.org/10.3311/pp.ch.2010-1.06

[18] Szabados, E., Srankó, D. F., Somodi, F., Maróti, B., Kemény, S., Tungler, A. "Wet oxidation of dimethylformamide via designed experiments approach studied with Ru and Ir containing Ti mesh monolith catalysts." Journal of Industrial and Engineering Chemistry. 34, pp. 405-414. 2016. https://doi.org/10.1016/j.jiec.2015.12.019

[19] Sági, G., Kovács, K., Bezsenyi, A., Csay, T., Takács, E., Wojnárovits, L. "Enhancing the biological degradability of sulfamethoxazole by ionizing radiation treatment in aqueous solution." Radiation Physics and Chemistry. 124, pp. 179-183. 2016. https://doi.org/10.1016/j.radphyschem.2016.02.009 
[20] Kozmér, Z., Takács, E., Wojnárovits, L., Alapi, T., Hernádi, K., Dombi, A. "The influence of radical transfer and scavenger materials in various concentrations on the gamma radiolysis of phenol." Radiation Physics and Chemistry. 124, pp. 52-57. 2016.

https://doi.org/10.1016/j.radphyschem.2015.12.011

[21] Kovács, K., He, S., Míle, V., Földes, T., Pápai, I., Takács, E., Wojnárovits, L. "Ionizing radiation induced degradation of monuron in dilute aqueous solution." Radiation Physics and Chemistry. 124, pp. 191-197. 2016. https://doi.org/10.1016/j.radphyschem.2015.10.028
[22] De la Cruz, N., Giménez, J., Esplugas, S., Grandjean, D., De Alencastro, L. F., Pulgarin, C. "Degradation of 32 emergent contaminants by UV and neutral photo-fenton in domestic wastewater effluent previously treated by activated sludge." Water Research. 46(6), pp. 1947-1957. 2012. https://doi.org/10.1016/j.watres.2012.01.014

[23] http://www.eb-tech.com

\section{Corrigendum}

The paper was online published on 24th July 2017 with the following author list and affiliations:

Erika Szabados ${ }^{1}$, Andrea Jobbágy ${ }^{2}$, Péter Mizsey³, Gábor Tardy², Cesar Pulgarin ${ }^{4}$, Stefanos Giannakis ${ }^{4}$, Erzsébet Takács ${ }^{5}$, László Wojnárovits ${ }^{5}$, Magdolna Makó ${ }^{6}$, Zénó Trócsányi ${ }^{7}$, Antal Tungler ${ }^{{ }^{*}}$

${ }^{1}$ Department of Surface Chemistry and Catalysis, Centre for Energy Research, Hungarian Academy of Sciences, 1525 Budapest, 114 P.O.B. 49, Hungary

${ }^{2}$ Department of Biotechnology and Food Science, Budapest University of Technology and Economics, H-1521 Budapest, P.O.B. 91, Hungary

${ }^{3}$ Department of Chemical and Environmental Process Engineering, Budapest University of Technology and Economics, H-1521 Budapest, P.O.B. 91 , Hungary

${ }^{4}$ Institut des Sciences et Ingénierie Chimiques, GGEC, EPFL, Bât. CH, 1015 Lausanne, Switzerland

${ }^{5}$ Department of Radiation Chemistry, Centre for Energy Research, Hungarian Academy of Sciences, 1525 Budapest, 114 P.O.B. 49, Hungary

${ }^{6}$ Budapest Sewage Works, 1087 Budapest, Asztalos Sándor út 4., Hungary

${ }^{7}$ Geosan Ltd., 1118 Budapest, Brassó út 169-179., Hungary

The corrected author list and the affiliations were published on 17th August 2017:

Erika Szabados ${ }^{1}$, Andrea Jobbágy ${ }^{2}$, András József Tóth ${ }^{3}$, Péter Mizsey ${ }^{3,4}$, Gábor Tardy², Cesar Pulgarin ${ }^{5}$, Stefanos Giannakis ${ }^{5}$, Erzsébet Takács ${ }^{6}$, László

Wojnárovits ${ }^{6}$, Magdolna Makó ${ }^{7}$, Zénó Trócsányi ${ }^{8}$, Antal Tungler ${ }^{*}$

${ }^{1}$ Department of Surface Chemistry and Catalysis, Centre for Energy Research, Hungarian Academy of Sciences, 1525 Budapest, 114 P.O.B. 49 , Hungary

${ }^{2}$ Department of Biotechnology and Food Science, Budapest University of Technology and Economics, H-1521 Budapest, P.O.B. 91, Hungary

${ }^{3}$ Department of Chemical and Environmental Process Engineering, Budapest University of Technology and Economics, H-1521 Budapest, P.O.B. 91, Hungary

${ }^{4}$ University of Miskolc, Hungary

${ }^{5}$ Institut des Sciences et Ingénierie Chimiques, GGEC, EPFL, Bât. CH, 1015 Lausanne, Switzerland

${ }^{6}$ Department of Radiation Chemistry, Centre for Energy Research, Hungarian Academy of Sciences, 1525 Budapest, 114 P.O.B. 49, Hungary

${ }^{7}$ Budapest Sewage Works, 1087 Budapest, Asztalos Sándor út 4., Hungary

${ }^{8}$ Geosan Ltd., 1118 Budapest, Brassó út 169-179., Hungary 